\title{
LA NECESARIA TUTELA COLECTIVA DE LAS AFECTACIONES PLURALES A LOS INTERESES DE LOS CONSUMIDORES Y USUARIOS
}

\author{
THE NEED FOR A CLASS ACTION TO REDRESS CONSUMER MASS TORTS
}

Sergi Corominas Bach

\author{
Doctor Internacional en Derecho Procesal. Profesor de Derecho Procesal en la \\ Universidad Católica San Antonio de Murcia (UCAM). E-mail: scorominas@ucam.edu
}

Convidado

Doi: $10.5585 /$ rdb.v18i7.802

RESUMEN: El comercio electrónico ha conllevado una rotura del paradigma clásico "consumidor local-empresario local" que nos obliga a replantear la eficacia del Derecho de Consumo como medida de protección de los intereses de los consumidores y usuarios. Este trabajo estudia especialmente aquellos supuestos en los que la entidad de la afectación o daño es ínfimo pero plural, ya que la tutela individual inicialmente prevista deviene, por la proporción entre la indemnización a percibir y los gastos del respectivo proceso judicial, un importante desincentivo económico. El resultado es, no solo una posible vulneración del derecho de acceso a la jurisdicción del artículo 24 de nuestra constitución, sino la consiguiente falta de tutela de estos daños masivos. A través del estudio de las características de estos intereses y los elementos esenciales de su tutela, el autor postula la necesidad de tutelar estos supuestos a través de un único proceso colectivo con el que, además de romper con la barrera económica apuntada, se tutelen los intereses de la totalidad de consumidores afectados.

Palabras Clave: Acciones colectivas. Consumidores y usuarios. Daños masivos.

\begin{abstract}
The e-commerce has led to a rupture of the classic paradigm of "local consumerlocal enterprise" and to the consequent crisis of Consumer Law as a tool to protect the interests of consumers. This work studies, specially, those cases in which the entity of the affection is low but plural, as the individual redress initially stablished becomes an economic obstacle because of the proportion between the individual sum to perceive and the costs of litigation. The result is, not only the possible violation of the right of access to justice (article 24 of the Spanish Constitution), but also the lack of an effective redress of those mass torts. Starting with an analysis of the characteristics of those interests and the essential elements of their redress, the author defends the need to stablish a collective action in order the break the economic barrier and repair mass torts to consumers' interests.
\end{abstract}

keywords: class actions. Consumers. Mass torts

SUMARIO: Introducción. 1. El concepto de intereses pluriindividuales homogéneos . 2. Características de los intereses pluriindividuales homogéneos. 3. Elementos esenciales de la tutela de los intereses pluriindividuales homogéneos. 4. Fundamento de la tutela colectiva de los intereses pluriindividuales homogéneos. Conclusiones. Bibliografía. 


\section{INTRODUCCIÓN}

El Derecho del Consumo busca proteger los intereses de consumidores y usuarios en la adquisición de productos y servicios, de tal forma que cuando un consumidor sufre un perjuicio derivado de su actuación en el mercado, el ordenamiento jurídico le permite acudir a la jurisdicción para la tutela de la afectación que ha sufrido. No obstante, el consumidor afectado únicamente iniciara el proceso individual respectivo si la cuantía indemnizatoria a percibir es tal como para correr los riesgos de sufragar las costas procesales en caso de perder dicho litigio.

En el reciente caso Volkswagen, por ejemplo, la considerable entidad del daño sufrido por el consumidor individual permitía a éste iniciar el respectivo proceso para la tutela exclusiva de su interés.

No obstante, ¿qué sucedería en caso que dicho daño fuera menor? Si bien a nivel individual dicha cuestión puede parecer baladí, ante daños masivos a los intereses de los consumidores y usuarios por parte grandes empresas internacionales, estamos hablando de sumas económicas muy elevadas que, a su vez, pueden tener un efecto disuasorio, en tanto en cuanto las empresas establecerán mediadas para evitar la reiteración del daño producido.

Por esta misma razón, a continuación estudiaremos, en primer lugar, los tipos de intereses en estos casos, para, para posteriormente tratar sus elementos característicos. En la parte central del trabajo nos centraremos en los medios de tutela establecidos y su efectividad. A continuación, finalizaremos este trabajo con el estudio de las acciones colectivas como medio para reparar los daños masivos a los intereses de los consumidores y usuarios.

Sin más, es el momento de entrar a analizar detenidamente los intereses de todos estos consumidores y usuarios susceptibles de ser afectados por un misma actividad empresarial.

\section{EL CONCEPTO DE INTERESES PLURIINDIVIDUALES HOMOGÉNEOS}

Los intereses pluriindividuales homogéneos son intereses individuales de las personas que integran un colectivo determinado cuya afectación presenta elementos fáctico-causales comunes que requieren una tutela colectiva o conjunta de los daños individuales. En otras palabras, los intereses pluriindividuales homogéneos son intereses individuales de los miembros de un grupo o clase que se han visto afectados de un modo cuantitativo y/o cualitativamente igual por una determinada actividad empresarial. Un concepto que también acoge el Código Modelo de Proceses Colectivos para Iberoamérica de 2003 que, partiendo del estudio de la ya tradicional dicotomía de intereses difusos y colectivos, abrió, de este modo camino a las acciones reparadoras de los perjuicios individualmente sufridos (correspondiendo, en el sistema norteamericano, a las class actions for damages). De hecho, las acciones colectivas buscan, en síntesis, permitir que estos sujetos individual y comúnmente afectados por una actividad ilícita puedan unirse en una única posición procesal y ejercitar una acción colectiva de indemnización para evitar, de esta manera, que la poca entidad de la indemnización en los llamados "daños masivos" pueda suponer una barrera en el acceso a la tutela judicial de los intereses afectados ${ }^{1}$.

\footnotetext{
${ }^{1}$ A nivel europeo, cabe destacar la reciente Recomendación de 11 de junio de 2013. En concreto, así lo establece el punto 14 de la Resolución del Parlamento Europeo, de 2 de febrero de 2012, sobre «Hacia un planteamiento europeo coherente del recurso colectivo» (2011/2089(INI)) (2013/C 239 E/05) y el considerando 11 de la Recomendación de la Comisión de 11 de junio de 2013 sobre los principios comunes aplicables a los mecanismos de recurso colectivo de cesación o de indemnización en los Estados miembros en caso de violación de los derechos reconocidos por el Derecho de la Unión (2013/396/UE) (DO L 201/60). A nivel español y a mero título de ejemplo, encontramos la STS 45/2012 en la que rotura de una prótesis implantada en la vena subclavia izquierda -stent- produce daños continuados al sujeto (FJ. 2). Este apartado será desarrollado en la parte relativa a la tutela de los intereses pluriindividuales homogéneos.
} 


\section{CARACTERÍSTICAS DE LOS INTERESES PLURIINDIVIDUALES HOMOGÉNEOS}

La primera de las notas definitorias de esta tipología de intereses es la existencia de la colectividad afectada como grupo, únicamente a partir de la afectación individual de cada uno de los miembros de la misma.

A esta colectividad, por contraposición a la clase potencialmente afectada, la llamaré clase necesariamente afectada, ya que, como su propio nombre indica, en ésta todos los miembros habrán de haber padecido un daño similar derivado de la misma conducta empresarial lesiva de sus intereses, para que se constituya dicha colectividad. Por consiguiente, será ese daño cualitativamente o cuantitativamente homogéneo el requisito esencial.

Esta tipología de clase necesariamente afectada encaja con la idea de interés legítimo clásico centrado en la patrimonialidad e individualización sobre la que se configura la legitimación procesal de nuestro ordenamiento ${ }^{2}$. No obstante, la acción colectiva en esta materia tan solo se incorporó a nivel procesal en la Ley de Enjuiciamiento Civil 1/2000, limitándose al ámbito de los consumidores y usuarios por el régimen establecido en la $\mathrm{CE}^{3}$. Sin duda alguna, los perjudicados en esta materia son los que más frecuentemente requieren ese tipo de tutela jurisdiccional colectiva. No obstante, se han dejado fuera intereses que se contemplan en el ámbito americano, como son los daños masivos por vertidos contaminantes o por rotura de presas $^{4}$, o, como supuesto paradigmático de la crisis financiera actual, la protección de los inversores. En esta materia, tal y como apunta CARBALLO PIÑEIRO, los inversores deben haber hecho la inversión entrando dentro del concepto de consumidor para poder utilizar la acción colectiva prevista en el artículo 11.2 de la Ley de Enjuiciamiento Civil ${ }^{5}$.

En este sentido, en Estados Unidos, el ámbito objetivo de las acciones colectivas no está tan limitado, de tal modo que las acciones colectivas norteamericanas se clasifican en función de si se refieren a daños masivos (mass torts), valores y acciones (securities and shareholders) $\mathrm{u}$ otros daños financieros (other injury claims).

En consecuencia y a diferencia de los intereses propiamente grupales, no puede caber una tutela preventiva de la afectación, sino que la tutela sólo puede comprenderse como respuesta a la producción del daño. Es decir, la tutela judicial puede exigirse exclusivamente cuando se haya producido la afectación de los intereses individuales, ya que, como su propio nombre indica y a pesar de su tutela colectiva, se trata de intereses individuales que se ejercitan conjuntamente en juicio y, como tal, tienen rasgos comunes.

En cuanto al objeto, cabe apuntar que los intereses pluriindividuales homogéneos son intereses individuales y, más allá de la procedencia o no de la tutela colectiva cuando éstos se ven afectados por una misma conducta, su objeto es perfectamente divisible y valorable económicamente. Por ende, el hecho de que se permita solicitar la reparación de forma conjunta no impediría que cada uno de los afectados pudiera ejercer individualmente o mediante una figura litisconsorcial su acción, ya que el objeto de esta tipología de intereses puede fragmentarse en cuantos afectados existan. En el ordenamiento jurídico español, el litisconsorcio requiere que las acciones se funden en el mismo título o causa de pedir (art. 12.1 LEC) y persigue la economía procesal mediante la discusión de los distintos asuntos en un único procedimiento y sentencia. Dicho esto, también conviene señalar que el litisconsorcio no parece adecuado para la tutela de los intereses pluriindividuales homogéneos, ya que la sentencia que ponga fin a un procedimiento iniciado a través de esa institución procesal debe contener tantos pronunciamientos separados cuantos sean los objetos procesales, al tratarse de pretensiones

\footnotetext{
${ }^{2}$ Apartado VII de la Exposición de Motivos de la Ley 1/2000, de Enjuiciamiento Civil.

${ }^{3}$ Esencialmente, en los artículos 6,7, 11, 11 bis, 13, 15, 221, 222 y 519 de la Ley de Enjuiciamiento Civil.

${ }^{4}$ Mejdrech v. Met-Coil Systems Corp. 319 F.3d 910 C.A.7 (III), 2003.

5 CARBAllo PIÑEIRO, L., Protección de inversores, acciones colectivas y derecho internacional privado, en Revista de Derecho de Sociedades, 37/2011, Tomo 2.
}

Revista de Direito Brasileira | São Paulo, SP | v. 18 | n. 7 | p. 438 - 462 | Set./Dez. 2017 
distintas que pueden estimarse o desestimarse independientemente. Tanto es así que los actos de disposición de las partes sólo afectan a la parte que los ha llevado a cabo y nunca a los demás litisconsortes. Una autonomía que también se refleja en la defensa, ya que las partes no deben actuar defendidas por un mismo abogado o representadas por un mismo procurador; además, las costas serán sufragadas por cada uno de ellos si fueron vencidos, según se establece en el artículo 394 de la LEC 6 .

Dicho esto, y aún en el caso que se pudiera proceder a dicha constitución, el litisconsorcio debería englobar a un gran número de afectados, ya que la afectación individual suele caracterizarse por ser de muy poca entidad en relación con las costas procesales y tasas judiciales respectivas. En consecuencia, una tutela colectiva a través de la figura del litisconsorcio resultaría inadecuada, ya que los costes del proceso judicial resultarían aún superiores a la suma de las indemnizaciones individuales.

Asimismo, el carácter individual de estos intereses y la divisibilidad de su objeto conlleva una relación inmediata del sujeto con el objeto que permite al primero gozar, en su concepción clásica y sin limitación alguna, de la titularidad y disposición sobre el interés afectado. Consiguientemente, el sujeto afectado por un daño masivo puede iniciar un proceso individual para solicitar la tutela de sus derechos, puede acordar una transacción o realizar todos aquellos actos que requieran de una titularidad plena de los intereses y derechos en juego, sin que el resultado del proceso o de estos actos puedan tener un efecto para los otros afectados por el acto generador del daño masivo.

No obstante, hay dos características que presenta el daño en estos supuestos que, a pesar que no impongan a nivel teórico una limitación de las facultades de disposición anteriormente apuntadas, pueden suponer una barrera en el acceso a la jurisdicción de este tipo de intereses colectivos.

Por un lado, la entidad del daño suele ser económicamente irrisoria en comparación con las costas y tasas judiciales que los afectados deberían afrontar en su tutela individual, ya que estamos tratando con supuestos de consumo que raramente - y debo decir que afortunadamenteconllevan daños de gran entidad para los afectados ${ }^{7}$. Precisamente, la poca cuantía de la indemnización a percibir a resultas de la poca entidad del daño padecido, es el elemento que disuade por lo general a los afectados del inicio de un proceso individual en el que tendrían que abonar unas altas cuantías en concepto de costas, tasas judiciales y otros gastos, junto con el riesgo que se dicte sentencia desfavorable a su pretensión.

Ello no obstante la multiplicidad de afectados por un mismo hecho o bajo unas características del daño comunes, plantea una posible solución a este problema. De hecho, este carácter plural y común de la afectación es la segunda de las características que presenta el daño en los intereses pluriindividuales homogéneos. Normalmente, la afectación es producto de una actividad (lícita o ilícita) por parte de un operador jurídico que, más allá de afectar las normas imperativas de protección a los consumidores y usuarios, conlleva la afectación de los intereses individuales de cada uno de los consumidores de un determinado producto o servicio.

\footnotetext{
${ }^{6}$ LÓPEZ JIMÉNEZ, R., Comentarios prácticos a la LEC. Arts. 12 y 420, en Indret: Revista para el Análisis del Derecho, ISSN-e 1698-739X, Nº. 4, 2004.

${ }^{7}$ Como excepciones, mencionar el caso del aceite de colza (Sentencias del Tribunal Supremo de 23 abril 1992 y núm. 895/2007 de 26 de setiembre. Hechos del caso: El aceite de colza siempre ha tenido aplicaciones industriales. Para evitar su desvío para el consumo de mesa, la normativa española permitía la importación de aceite de colza para usos industriales, pero obligaba a desnaturalizar el aceite de colza, haciéndolo inviable como alimento. En 1973, sin embargo, industriales importadores de aceite de colza pidieron autorización al Laboratorio Central de Aduanas para utilizar anilina, un producto tóxico pero no venenoso, como agente desnaturalizante y el permiso fue concedido. Años después, algunos industriales se concertaron para importar aceite de colza desnaturalizado, invertir el proceso de desnaturalización y vender el aceite para su consumo alimenticio, causando, como resultado, la muerte de 1.100 personas y el envenenamiento de otras 60.000) o la reciente sentencia sobre la Talidomida.
} 
Por esta misma razón y sin ánimo de anticiparme a lo que se verá más adelante, la tutela colectiva de esta tipología de intereses se postula como la solución para conseguir, por un lado, la reparación de los daños de los consumidores afectados y, por el otro, en el caso que se haya infringido, el cumplimiento de la normativa imperativa tuitiva de los derechos del colectivo social jurídicamente protegido.

En esta sede, procede examinar algunos ejemplos jurisprudenciales de protección de los intereses pluriindividuales homogéneos no sólo para observar las características que acabamos de señalar, sino también porque nos servirá para entender mejor las modalidades de tutela que precisan.

Tal y como he apuntado, los "daños masivos" suelen ser los supuestos paradigmáticos de afectación de los intereses pluriindividuales homogéneos. Sin embargo, estos daños pueden derivar de la infracción de una normativa imperativa y tuitiva de los intereses de los consumidores y usuarios o bien de un acto que, si bien no es contrario a la normativa imperativa, ha provocado una afectación de los intereses de los consumidores y usuarios individuales.

En este sentido, cuando esta afectación sea consecuencia de la inobservancia de las normas ius cogens en materia de consumo, podremos hablar, primeramente, de una afectación de los intereses individuales homogéneos de los miembros del colectivo que, al mismo tiempo, ha generado una lesión a los intereses propiamente grupales, por vulneración de una norma imperativa tuitiva de los intereses de los consumidores y usuarios.

Un supuesto reciente que reúne estas características es el caso de la Talidomida. La Talidomida es un fármaco que fue comercializado entre los años 1958 y 1963 como sedante y como calmante de las náuseas durante los tres primeros meses de embarazo (hiperémesis gravídica). Sin embargo, este producto provocó miles de nacimientos de bebés afectados de focomelia, anomalía congénita que se caracterizaba por la carencia o excesiva cortedad de las extremidades. En la comercialización de este producto no se realizaron los estudios con el margen temporal suficiente como para comprobar la no producción de efectos secundarios, infringiendo la normativa vigente en aquel momento. Además de la afectación de los intereses propiamente grupales que se deriva, dicha infracción conllevó un daño individual de los consumidores que tomaron este medicamento.

Por el contrario, en aquellos casos que únicamente se trate de una eventual afectación a una pluralidad de consumidores y usuarios, hablaremos exclusivamente de intereses pluriindividuales homogéneos. La casuística en este tipo de supuestos aumenta:

En primer lugar, el caso por excelencia es la sentencia Opening, nombre de la escuela de idiomas que ofertaba determinados cursos que, si bien no llegaron a realizarse por el cierre de la misma, habían sido suscritos por una multiplicidad de consumidores y usuarios ${ }^{8}$. En este supuesto, los contratos para dar cursos de inglés concertados por Opening y los correlativos contratos de financiación de estos cursos en principio no son contrarios a ninguna ley de protección de consumidores, sino que constituyen actividades lícitas y útiles para los consumidores mientras se desarrollen conforme a lo pactado. El hecho dañoso no lo constituyen los referidos contratos, sino el incumplimiento de sus obligaciones por parte de Opening como consecuencia de una situación de insolvencia económica. No se trata, por tanto, de que Opening cese de firmar contratos o de producir efectos los concertados por ser los mismos lícitos, sino de proteger a los consumidores de los efectos de su incumplimiento provocado por su insolvencia.

\footnotetext{
${ }^{8}$ SAP de Sevilla de 22 enero 2004 o SAP de Madrid, núm. 10/2006 de 16 de enero, comentada ésta última por LLAMAS POMBO, E., «Caso Opening», sentido común y sentido jurídico en Práctica de Derecho de Daños, $\mathrm{N}^{\circ} 39$, Sección Editorial, Junio 2006. Sobre el mismo caso véase también: BUSTOS LAGO, J. M., Incumplimiento de la prestación de servicios financiada a través de un contrato de préstamo al consumo. Algunas precisiones a propósito del caso "Opening English School", en Actualidad Jurídica Aranzadi, núm. 564; y, desde una perceptiva más amplia y a modo de lege ferenda, VÁZQUEZ SOTELO, J. L., El proceso de acciones colectivas (necesidad de su implantación en España), en Actualidad Civil, No 16, Sección A Fondo, Quincena del 16 al 30 Sep. 2011, tomo 2, pp. 1794 y ss..
}

Revista de Direito Brasileira | São Paulo, SP | v. 18 | n. 7 | p. 438 - 462 | Set./Dez. 2017 
En este sentido, se trata de la tutela de daños generados a partir de una conducta que, si bien es lícita, ha generada una pluralidad de daños protegidos por el ordenamiento jurídico español y, por ende, dignos de tutela9.

En el mismo sentido, cabe destacar la Sentencia de la Audiencia Provincial de A Coruña de 26 de mayo de 2006 por la que se solicita la resolución de crédito al consumo para financiar un curso de inglés. El problema planteado consistía en que, si bien las academias que ofertaban los cursos de inglés cerraron masivamente, los alumnos tuvieron que seguir pagando las cuotas mensuales de devolución de un préstamo a través del cual una tercera entidad, normalmente banco o caja de ahorros, financiaba el importe total del curso. De este modo, si bien el cierre de las academias no suponía ningún problema jurídico en cuanto se resolvían los contratos de servicios de enseñanza por incumplimiento de una de las partes, las entidades financieras acreedoras de los contratos de préstamo procedieron a reclamar judicialmente y a ejecutar el importe de las cuotas impagadas. A partir de esta situación, los alumnos perjudicados solicitan a través de una organización de consumidores y usuarios la resolución del contrato de servicios de enseñanza, la resolución del contrato de préstamo y la devolución de las cantidades pagadas a la entidad financiera, ya que estuvieron pagando por un servicio que no recibían. Si bien los contratos que habían firmado los estudiantes contenían determinadas cláusulas para evitar la aplicación de la Ley de Crédito al Consumo y para impedir la resolución del contratado de crédito al consumo en el caso que se produjera la resolución del contrato principal (contrato de enseñanza), la Audiencia considera que existe un desequilibrio entre las partes contratantes del cual eran conscientes tanto la academia de idiomas como la entidad bancaria que concedía la financiación, por lo que no puede sostenerse que la entidad financiera firmaba los contratos de crédito al margen del contrato de enseñanza, cuando eran los propios empleados de la academia de idiomas quienes ofertaban al cliente esta posibilidad ${ }^{10}$.

Por último, encontramos la Sentencia del Tribunal Supremo de 15 de julio de 2010, supuesto en el que se produjeron importantes retenciones en la Autopista de Burgos a Armiñón, debido a múltiples accidentes producidos por un fuerte temporal de nieve en la tarde del día 27 de febrero de 2004. Ante dichas circunstancias, no tan sólo no se alertó a los conductores de los mismos, sino que se permitió que fueran accediendo a la autopista a pesar del estado en que ésta se hallaba ${ }^{11}$. Como consecuencia de ello, más de 6000 personas se quedaron atrapadas en la carretera o se vieron obligadas a pernoctar en polideportivos y centros diversos de las inmediaciones. Cabe destacar que, una vez producidos dichos daños, tampoco hizo nada la entidad concesionaria para paliarlos. Es más, cuando se restableció la circulación a lo largo de la mañana y el mediodía del día 28 de febrero de 2004, los vehículos que habían quedado atrapados tuvieron que pagar el correspondiente canon de peaje para poder abandonarla ${ }^{12}$. A partir de estos hechos, Ausbanc Consumo presentó una demanda ejercitando una acción colectiva en defensa de intereses y derechos de consumidores y usuarios, en reclamación de cantidad, fundada en el incumplimiento en la prestación de un servicio público, así como en el enriquecimiento sin causa y cobro de lo indebido por parte de la demandada. El Tribunal Supremo, a partir de lo expuesto, confirma la admisibilidad del ejercicio de acciones colectivas resarcitorias, sin necesidad de que se hallen expresamente reguladas o tipificadas legalmente ${ }^{13}$.

\footnotetext{
${ }^{9}$ LLAMAS POMBO considera de loable la Sentencia de la Audiencia Provincial de Madrid núm. 10/2006, de 16 de enero, al traer un poco de sentido y agudeza jurídica (LLAMAS POMBO, E., Caso openig, op. cit.).

${ }^{10}$ LLAMAS POMBO, E., Reflexiones sobre derecho de daños: casos y opiniones, La Ley, Madrid, 2010, pp. 119 y ss.

${ }^{11}$ SAP Burgos núm. 347/2006 de 31 de julio.

${ }^{12}$ Para un análisis de la Sentencia del Tribunal Supremo núm. 473/2010, de 15 de julio ver GASCÓN INCHAUSTI, F., Acción colectiva de los usuarios frente a la entidad concesionaria de una autopista como consecuencia de las retenciones provocadas por una nevada (algunas consideraciones a la luz de la Sentencia del Tribunal Supremo de 15 de julio de 2010), en Aranzadi Civil-Mercantil, núm. 6/2011 (Estudio).

${ }^{13}$ Sentencia del Tribunal Supremo núm. 473/2010, de 15 de julio.
}

Revista de Direito Brasileira | São Paulo, SP | v. 18 | n. 7 | p. 438 - 462 |Set./Dez. 2017 
Como ha señalado GASCÓN INCHAUSTI, la regulación sectorial que prevé el ejercicio de acciones colectivas en defensa de los derechos e intereses de consumidores y usuarios componen un red básica como punto de partida iniciado por la Directiva 98/27/CE, red que, ante la novedad de esta materia y el desconocimiento de la existencia de instrumentos de tutela, no puede nunca interpretarse como una restricción al ejercicio de acciones diferentes a las reguladas pero con la misma finalidad, ya que dicha restricción sería contraria al espíritu que inspira la normativa comunitaria "de mínimos" en materia de defensa de los consumidores ${ }^{14}$. En este sentido y junto al efecto multiplicador que ha generado la adopción de la Directiva apuntada, la interpretación que hace el Tribunal Supremo respecto las acciones colectivas activas me parece jurídicamente correcta ${ }^{15}$.

\section{ELEMENTOS ESENCIALES DE LA TUTELA DE LOS INTERESES PLURIINDIVIDUALES HOMOGÉNEOS}

Hecha esta breve distinción, procedo a analizar dos aspectos que considero imprescindibles para el estudio de la tutela indemnizatoria como tutela de los intereses pluriindividuales homogéneos y los requisitos fácticos y jurídicos que deberán concurrir para que pueda ejercerse.

En primer lugar, presentaré un esquema muy sencillo de la protección de los intereses individuales en nuestro ordenamiento jurídico, ya que no puede olvidarse que los intereses pluriindividuales homogéneos son intereses estrictamente individuales de cada uno de los afectados que, por las razones que veremos a continuación, precisan de un proceso colectivo para su efectiva tutela.

Cuando una norma jurídica recoge un determinado derecho o interés lo convierten en un derecho o interés legítimo, esto es, este interés pasa a estar legalmente protegido por el ordenamiento jurídico. Protección que, a su vez, se concreta en la imposibilidad de afectación de estos derechos o intereses, sin perjuicio de aquellos casos en los que su afectación se considere legalmente aceptable a partir de un juicio de ponderación con otros derechos o intereses igualmente protegidos.

La dificultad se plantea cuando se afectan estos derechos e intereses infringiendo la legalidad vigente. Entonces, el ordenamiento jurídico debe ofrecer la posibilidad a los titulares de los derechos e intereses afectados de exigir la restauración - si es posible- o indemnización del daño creado, ya que, en caso contrario, la protección resultaría ineficaz. Sin embargo, ¿resulta suficiente la tutela individual para la protección de este tipo de intereses?

Cabe afirmar que la tutela individual en estos casos es insuficiente debido a las características que presentan los intereses pluriindividuales homogéneos en los daños masivos. En este sentido, CAPPELLETI apunta varios elementos a considerar en el acceso a la justicia de este tipo de intereses ${ }^{16}$. En primer lugar, hace mención a los altos costes de litigación, diferenciando entre aquellos países en los que se aplica la "american rule" y aquellos en los que se aplica la regla de "quien pierde paga" o "winner takes all"

\footnotetext{
${ }^{14}$ GASCÓN INCHAUSTI, F., Acción colectiva, op. cit..

${ }^{15}$ En el mismo sentido: GARCÍA VILA, M., Las condiciones generales de la contratación: aspectos procesales, Valencia, 2006, pp. 124-130; y LLAMAS POMBO, E., Requisitos de la acción colectiva de responsabilidad civil, en Diario La Ley, núm. 7141, 24 de marzo de 2009.

16 CAPPELletTI, M., Access to justice, Promising institutions, Alphennaandenrijn, Sijthoff and Noordhoff, Giuffrè, Milan, 1978-1979, Vol. II, Libro I, pp. 3 y ss..

17 Se trata de un trabajo pionero en el estudio comparado de la tutela colectiva, cuya extensión alcanza las regulaciones de Australia, Austria, Bulgaria, Canadá, Chile, China, Colombia, Inglaterra, Francia, Alemania, Holanda, Hungría, Indonesia, Israel, Italia, Japón, México, Polonia, la Unión Soviética, España, Estados Unidos y Uruguay (CAPPELLETTI, M., Acces to justicie, op. cit., pp. 141-204, 205-230, 231-246, 247-344, 345-370, 371Revista de Direito Brasileira | São Paulo, SP | v. 18 | n. 7 | p. 438 - 462 | Set./Dez. 2017
} 
costas en los países europeos es la de quien pierde paga, cosa que comporta un desconocimiento de la cuantía que deberá afrontar la pluralidad de afectados en el supuesto que no se estimen sus pretensiones; frente a la certeza que tendrá la parte en aquellos ordenamiento jurídicos en los que exclusivamente deba abonar sus costas procesales con independencia del carácter estimatorio de la sentencia (american rule). En segundo lugar, como también he mencionado con anterioridad, hace referencia a la poca entidad de las demandas de los individuos afectados por un daño masivo como elemento que puede obstaculizar el acceso a la justicia de este tipo de intereses (small claims). Precisamente, la desproporción entre la indemnización individual a percibir y las costas y tasas procesales que deberán abonar los afectados es, desde mi punto de vista, la principal razón que fundamenta el ejercicio de las acciones colectivas como tutela de este tipo de intereses.

Asimismo, CAPPELLETTI considera relevante el factor tiempo para determinar la efectividad del acceso a la jurisdicción. El derecho de acceso a la jurisdicción obliga al Estado a ofrecer una tutela judicial a los derechos e intereses afectados que, para su efectividad, debe dispensarse dentro de un lapso prudencial de tiempo. En consecuencia, una tutela tardía o con excesivas dilaciones no sería acorde con el derecho de acceso a la jurisdicción, con la consiguiente legitimación para que el sujeto titular de los derechos o intereses pueda instar un proceso de amparo en base a la vulneración del derecho a la tutela judicial efectiva.

Por último, no cabe olvidar la posibilidad de que, dentro de los afectados, existan sujetos que, si bien no adoptarán una actitud activa para la tutela de sus intereses afectados en estos supuestos, se beneficiarán de la sentencia que recaiga en el proceso (los llamados “free riders $)^{18}$.

\section{FUNDAMENTO DE LA TUTELA COLECTIVA DE LOS INTERESES PLURIINDIVIDUALES HOMOGÉNEOS.}

Una vez apuntados los elementos esenciales de los intereses pluriindividuales homogéneos en cuanto al derecho de acceso a la jurisdicción, voy a partir de éste último derecho para justificar la necesidad de una tutela colectiva de estos intereses.

El derecho de acceso a la jurisdicción es un derecho fundamental que, en el ordenamiento jurídico español, está regulado en el artículo 24 de la Constitución Española de 1978. Antes de entrar en el contenido del mismo, es necesario apuntar la diferenciación entre el derecho formal de acceso a la jurisdicción y el derecho positivo consecuencia de la protección de los derechos humanos por parte del Estado como parte de su carácter social ${ }^{19}$. La concepción formal de este derecho no conllevaba una obligación de actuación por parte de los Estados, ya que al tratarse de un derecho natural y, como tal, previo al Estado, no requería protección estatal alguna $^{20}$.

Con el advenimiento de los derechos sociales en las principales constituciones europeas del siglo XX, se destaca la importancia del derecho procesal en su vertiente práctica y la necesidad de tutela de esta tipología de situaciones por parte de los Estados. La norma pionera en regular esta tarea fue el Código Australiano de 1895, en el que el juez tenía la obligación de igualar la posición de las partes en el proceso. En Europa, este carácter social intervencionista lo

394, 395-416, 417-478, 479-524, 527-578. 579-594, 595-616, 617-624, 625-648, 649-686, 687-762, 763-782, 783816, 817, 845-888, 889-912, 913-1024, 1025 y ss., respectivamente).

18 OLSON, The logic of Collective Action, Harvard University Press, Cambridge, 2002, p. 2965 y GARCIA SOBRECASES, F., Elección colectiva y provisión de bienes públicos [Microforma]: búsqueda de las soluciones al comportamiento free rider, Universitat de Valencia, Valencia, 1998.

${ }^{19}$ CALAMANDREI, P., Opere Giuridiche, Morano, Nápoles, 1968, pp. 183-210.

${ }^{20}$ CHAYES, The Role of the Judge in Public Law Litigation, en HARVARD LAW REVIEW, 89, 1976, pp. 10411048. 
encontramos en el Preámbulo de la Constitución Francesa de 1946, el artículo 3 de la Constitución Italiana y el artículo 28 de la Ley Fundamental de la República Federal Alemana ${ }^{21}$.

En síntesis, el derecho de acceso a la jurisdicción es el reconocimiento constitucional del derecho a buscar la protección jurisdiccional de los derechos como garantía fundamental ${ }^{22}$. Derecho que, con posterioridad a la Segunda Guerra Mundial, se interpreta como la manifestación del Derecho a la acción a través de dos elementos característicos: la efectividad y el trato equitativo ${ }^{23}$.

No obstante, esta función del estado como garante del derecho de acceso a la jurisdicción se construye alrededor del concepto tradicional de proceso civil entendido como instrumento a través del cual se realiza la tutela de aquellos derechos e intereses legalmente reconocidos ${ }^{24}$. Contrariamente a lo que ocurría con la identificación entre el derecho subjetivo y la acción en el pasado, el derecho de acceso a la jurisdicción incluye también aquellas situaciones jurídicamente relevantes en las que no hay un verdadero derecho subjetivo, sino un mero interés legítimo $^{25}$.

En un primer momento, sin embargo, la identificación entre el derecho subjetivo y la acción implicaba la exclusión del concepto de legitimación, ya que el único que podía ejercitar la

${ }^{21}$ El Preámbulo de la Constitución Francesa de 1946 establece: Proclama, asimismo, por ser especialmente necesarios en nuestra época, los siguientes principios politicos, económicos y sociales [...] Garantiza a todos, y especialmente al niño, a la madre y a los antiguos trabajadores, la protección de la salud, la seguridad material, el descanso y el ocio. Todo ser humano que, debido a su edad, su estado físico o mental o su situación económica, se encuentre incapacitado para trabajar, tiene derecho a obtener de la colectividad los medios de existencia necesarios. La Nación garantiza la igualdad de acceso del niño y del adulto a la instrucción, a la formación profesional y a la cultura. La organización de la enseñanza pública gratuita y laica en todos los niveles es un deber del Estado.

Por su parte, el artículo 3 de la Constitución Italiana de 1948: Todos los ciudadanos tendrán la misma dignidad social y serán iguales ante la ley, sin distinción de sexo, raza, lengua, religión, opiniones políticas ni circunstancias personales y sociales. Constituye obligación de la República suprimir los obstáculos de orden económico y social que, limitando de hecho la libertad y la igualdad de los ciudadanos, impiden el pleno desarrollo de la persona humana y la participación efectiva de todos los trabajadores en la organización política, económica y social del país.

Por último, el artículo de la Ley Fundamental de la República Federal Alemana: (1) El orden constitucional de los Länder deberá responder a los principios del Estado de Derecho republicano, democrático y social en el sentido de la presente Ley Fundamental. En los Länder, distritos y municipios, el pueblo deberá tener una representación surgida de elecciones generales, directas, libres, iguales y secretas. En los distritos y municipios, de acuerdo con el Derecho de la Comunidad Europea, el derecho de votar y de ser elegido lo tienen también las personas que posean la nacionalidad de un Estado miembro de la Comunidad Europea. En los municipios, en lugar de un cuerpo elegido podrá actuar la asamblea municipal. (2) Deberá garantizarse a los municipios el derecho a regular bajo su propia responsabilidad, dentro del marco de las leyes, todos los asuntos de la comunidad local. Las asociaciones de municipios tienen igualmente, dentro del marco de sus competencias legales y de acuerdo con las leyes, el derecho de autonomía administrativa. La garantía de la autonomía abarca también las bases de la propia responsabilidad financiera; estas bases incluyen una fuente tributaria que, junto con el derecho de fijar los tipos de recaudación, corresponde a los municipios y se rige por la respectiva capacidad económica.

(3) La Federación garantizará la conformidad del orden constitucional de los Länder con los derechos fundamentales y las disposiciones de los apartados 1 y 2.

${ }_{22}^{2}$ TARUFFO, M., Páginas sobre justicia civil, Marcial Pons, Madrid, 2009, pp. 31-35.

23 CAPPElletti, M., Access to justice, Promising institutions, Alphennaandenrijn, Sijthoff and Noordhoff, Giuffrè, Milan, 1978-1979, Vol. II, Libro I, pp. 9 y ss.

24 DE LA OLIVA, A., DIEZ-PICAZO, I., VEGAS TORRES, J., Curso de derecho procesal civil, Editorial Universitaria Ramón Areces, Madrid, 2012, pp. 138 y 139.

25 OROMÍ VALL-LLOVERA, S., Intervención de terceros en el proceso civil: facultades procesales del interviniente, Marcial Pons, Madrid, 2007, pp. 37-39.

Como ejemplos de "interés legítimo" encontramos las siguientes Sentencias del Tribunal Constitucional: núm. 31/2000, de 3 de febrero, núm. 124/2002, de 20 de mayo, núm. 112/2004, de 12 de julio, núm. 142/2004, de 13 de septiembre, núm. 45/2004, de 23 de marzo, núm. 173/2004, de 18 de octubre o núm. 172/2006, de 5 de junio.

Doctrinalmente, CABAÑAS GARCÍA diferencia entre derecho subjetivo, interés legítimo, interés colectivo e interés público en: La tutela judicial del tercero, Dijusa, Madrid, 2005, pp. 70, 72, 79 y 89, respectivamente.

Revista de Direito Brasileira | São Paulo, SP | v. 18 | n. 7 | p. 438 - 462 | Set./Dez. 2017 
acción individual era el particular titular del derecho subjetivo ${ }^{26}$. Tal y como recoge SAVIGNY, esta concepción partía de la teoría romana de la acción en la que ambos conceptos estaban estrechamente ligados ${ }^{27}$. WINDSCHEID y MUTHER, por su parte, fueron los pioneros en presentar una concepción dualista sobre el derecho subjetivo y la acción. Se distinguen dos derechos completamente distintos: el derecho subjetivo material frente a un particular de naturaleza privada y el derecho de acción de naturaleza pública contra el Estado ${ }^{28}$. En la doctrina española, TRAVESAS y BECEÑA se postulan como los primeros autores que reciben la concepción dualista descrita en nuestra doctrina ${ }^{29}$. Esta concepción evolucionará por la vía del proceso y conllevará el asentamiento de las bases para distinguir entre el titular del derecho subjetivo y el titular de la acción, es decir, las condiciones teóricas imprescindibles para poder hablar del concepto de legitimación ${ }^{30}$.

El interés legítimo, por otro lado, es el presupuesto indispensable de toda acción y consiste en una "situación jurídica material favorable cualificada por una facultad reaccional o impugnatoria que se otorga a su titular en caso de ser aquélla lesionada por una actuación antijurídica" 31 .

De esta definición cabe destacar los siguientes rasgos:

\begin{abstract}
${ }^{26}$ Acción comprendida como derecho subjetivo en pie de guerra (PUCHTA, citado por PEKELIS, Azione en Nuovo Digesto Italiano, vol. II, Torino, 1938, p. 93 y, en el mismo sentido, DEMOLOMBE, Ciurs de Code Napoleon, tomo IX, $4^{\circ}$ ed., París, 1870, núm. 338). Esta concepción inicial fue el punto de partida de la doctrina española, tal y como recoge GUTIEREZ-ALVIZ y CONRADI, Doctrina procesal español sobre la acción: 1830-1930, en Revista de Derecho Procesal Iberoamericana, 1979, 1, p. 28.

${ }^{27}$ SAVIGNY, Sistema de derecho romano actual, tomo IV, Madrid pp.7-10.

${ }^{28}$ WINDSCHEID, La "actio" del derecho civil romano desde el punto de vista del derecho actual, Düsselforf, 1856, La "actio". Replica a Th. Muller, Dusseldorf, 1857 y MUTHER, Sobre la doctrina de la "actio" romana, del actual derecho de acción, de la "litiscontestatio" y de la sucesión singular en las obligaciones, Erangen, 1857. Si bien ya CALAMANDREI señaló la diversidad de teorías de la acción (CALAMANDREI, La certezza del diritto e la responsabilità della dottrina, en Opere giuridiche, I, Napoli, 1965, p. 514) es preciso apuntar las principales teorías sobre la esencia de la acción, ya que posteriormente se desarrollaran aquellas relativas el carácter de la misma. En cuanto a teorías sobre la esencia de la acción, destaca la acción como derecho potestativo (CHIOVENDA, G., L'azione nel sistema dei diritti, en Saggi di Diritto Processuale Civile (1900-1930), Volume Primo, Società editrice "Foro Italiano", Roma 1930, pp. 3-99; Principii de Diritto Processuale Civile, Casa editrice Dott. Eugenio Jovene, Napoli, 1965, pp. 43-63; y Istituzioni di Diritto Processuale Civile, Volume I, Casa editrice Dott. Eugenio Jovene, Napoli, 1960, pp. 16-30); la acción como derecho subjetivo público (FAIREN GUILLÉN, V., Doctrina general de Derecho procesal, Bosch, Barcelona, 1990, p. 81; MORÓN PALOMINO, M., Derecho Procesal Civil (Cuestiones fundamentales), Marcial Pons, Madrid, 1993, p. 141; y DE LA OLIVA, A., Derecho Procesal Civil, I, Centro de Estudios Ramón Areces, 1991, pp. 140-142);y la acción como poder (MONACCIANI, L., Diritto Processuale Civile, I, Giuffrè, Milano, 1964, p. 56 o GUASP, J., Derecho Procesal Civil, Civitas, Madrid, 2003, p. 212).

Para un análisis de cada una de la teorías apuntadas, véase: SILGUERO ESTAGNAN, J., La legitimación de los grupos, Dykinson, Madrid, 1995, pp. 75-81 y MONTERO ARICA, GOMEZ COLOMER, J. L., MONTÓN REDONDO, A. y BARONA VILAR, S., Derecho jurisdiccional II: Proceso civil, Tirant lo Blanch, Valencia, 2011, pp. 72-76; así como GÓMEZ ORBANEJA, E., El ejercicio de los derechos, Cuadernos Civitas, Madrid, 1975 y CORDON MORENO, F., La legitimación en el proceso contencioso administrativo, EUN-SA, Pamplona, 1979.

${ }^{29}$ TRAVESAS, M. M., La defensa privada, en Revista de Derecho Privado, 1915, pp. 193-203; BECEÑA, F., Magistratura y justicia, Madrid, 1928, pp. 348-59 y Notas de derecho procesal civil, Madrid, 1932, pp. 47 y ss. (ver MONTERO, Aproximación a la biografía de Francisco Beceña, en Estudios de Derecho Procesal, Barcelona, 1981, p. 629.

${ }^{30}$ MONTERO AROCA, La legitimación colectiva de las entidades de gestión de la propiedad intelectual, Comares, Granada, 1997, pp. 18-22. Cabe destacar la teoría de la relación jurídica de BULOW (BULOW, La teoría de las excepciones procesales y de los presupuestos procesales, Ediciones Jurídicas Europa América, Buenos Aires, 1964, p. 2), cuya inutilidad es puesta en cuestión por MONTERO, El proceso no tiene naturaleza jurídica, en Revista de Derecho Procesal, 1, 1990, pp. 152-156.

${ }^{31}$ Esta definición y los rasgos apuntados han sido extraídos de: GUTIÉRRREZ DE CABIEDES E HIDALGO DE CABIEDES, P., La Tutela Jurisdiccional de los Intereses Supraindividuales: Colectivos y Difusos, Elcano (Navarra), 1999, p. 53.
\end{abstract}

Revista de Direito Brasileira | São Paulo, SP | v. 18 | n. 7 | p. 438 - 462 |Set./Dez. 2017 
"Situación subjetiva de relevancia jurídica". La situación subjetiva debe estar protegida mediante una norma jurídica para que pueda haber legitimación. En caso contrario, sería una situación no tutelada por el ordenamiento jurídico. Es decir, si bien constaría el elemento interno (facultas agendi) del interés, éste no gozaría del elemento externo caracterizado por la posibilidad de exigir su respeto ${ }^{32}$. Por consiguiente, de dicha situación subjetiva no siempre podría derivarse un derecho subjetivo. Sin embargo, una vez superado el concepto clásico de relación jurídica (correlación entre derecho subjetivo y obligación), cabe analizar si de una situación subjetiva no protegida normativamente podría emanar un interés legítimo. La diferencia entre derecho subjetivo e interés legítimo, recordamos, reside en la disposición y no en la protección, de tal modo que el interés legítimo únicamente implica un poder de reacción o un derecho subjetivo llamado reaccional $^{33}$. No obstante, dicho interés legítimo requiere también la protección de una norma para su existencia ${ }^{34}$. En este sentido, no podrá existir un interés jurídico ante la falta de protección normativa o relevancia jurídica de una determinada situación subjetiva.

"Situación jurídico-subjetiva material favorable". Se refiere a la situación subjetiva personal y fáctica que es subsumible en el marco subjetivo que prevé la norma jurídica. Por consiguiente, dicha situación jurídico-subjetiva material favorable es el elemento clave de la pretensión de tutela jurisdiccional.

"Facultad instrumental de reacción". Se trata de la previsión en la norma jurídica de la posibilidad de pedir la tutela jurisdiccional ante el cumplimiento del supuesto de hecho de la misma. Es decir, a partir de la lesión de la situación subjetiva protegida por la norma jurídica, el perjudicado ostentará un derecho subjetivo de reparación tutelable ante los tribunales.

En el presente trabajo se hablará de intereses colectivos y no de derechos colectivos debido al trato diferencial de la jurisprudencia española a los derechos subjetivos e intereses legítimos ${ }^{35}$. La mayor parte de esos pronunciamientos están relacionados con la vulneración del derecho a la tutela judicial efectiva que garantiza el artículo 24.1 de la Constitución Española.

\footnotetext{
${ }^{32}$ Entendido como la relación ideal existente entre una persona, acuciada por una necesidad, y el bien apto para satisfacer dicha necesidad. MONTERO AROCA, J, Introducción al Derecho Procesal. Jurisdicción, acción y proceso, Tecnos, Madrid, 1979, p. 88.

33 GÓMEZ ORBANEJA, E., El ejercicio de los derechos, Cuadernos Civitas., Madrid, 1975, p. 44. Más recientemente y en el mismo sentido, CAJARVILLE: "Puede concluir también en que se trata de un interés legítimo; la diferencia con el interés simple consiste que en este caso existen normas que encausan, regulan el comportamiento del sujeto pasivo de la eventual pretensión, pero ocurre que esas normas jurídicas que encausan la conducta del pretendido permiten que la pretensión sea legítimamente satisfecha pero permiten también que legítimamente no sea satisfecha; y entonces la diferencia con el derecho subjetivo consiste en que en este caso esas reglas que encausan el comportamiento del sujeto contra el que se dirige la pretensión hacen jurídicamente necesaria la satisfacción de ese interés cuando se actualiza como pretensión" (CAJARBILLE PELUFFO, J. P., Conceptos constitucionales definitorios de la legitimación del actor relaciones entre derecho subjetivo, interés legítimo e interés general, Conferencia Magistral dictada por el autor en las VII Jornadas Académicas del Tribunal de lo Contencioso Administrativo, con la Co-Dirección de la Procuraduría del Estado en lo Contencioso Administrativo, celebradas los días 5 y 6 de noviembre de 2012).

${ }^{34}$ Según la Sentencia del Tribunal Constitucional 62/1983, de 11 de julio, el interés legítimo es aquel protegido por el derecho en "contraposición a aquellos que no son objeto de tal protección. En el mismo sentido el Auto del mismo Tribunal 807/1985: "el derecho a la tutela judicial efectiva (Art. 24 .1 CE) que se reconoce a todas las personas en el ejercicio de sus derechos e intereses legítimos otorga legitimación a cuantos ciudadanos ostenten el interés protegido por el derecho. Dicho interés puede ser existente aunque sea de modo indirecto o reflejo (STS de 24 de septiembre de 1992, recurso núm. 4450/1990).

${ }^{35}$ En países como Colombia, por ejemplo, se habla de verdaderos derechos de orden colectivo para la satisfacción de necesidades comunes (Sentencia de la Corte Constitucional de Colombia No. C 215/1999, de 14 de abril).
}

Revista de Direito Brasileira | São Paulo, SP | v. 18 | n. 7 | p. 438 - 462 | Set./Dez. 2017 
Según el mencionado precepto, “todas las personas tienen derecho a obtener la tutela efectiva de los jueces y tribunales en el ejercicio de sus derechos e intereses legítimos sin que, en ningún caso, pueda producirse indefensión", 36.

El Tribunal Constitucional ha perfilado el interés legítimo, digno de recibir la tutela jurisdiccional que garantiza el artículo 24.1 CE, como "cualquier ventaja o utilidad jurídica derivada de la reparación pretendida, ${ }^{37}$, remarcando que se trata de un:

"Interés legítimo, real y actual, que puede ser tanto individual como corporativo o colectivo y que también puede ser directo o indirecto, en correspondencia con la mayor amplitud con la que se concibe en el texto constitucional la tutela judicial de la posición del administrado y la correlativa necesidad de fiscalizar el cumplimiento de la legalidad por parte de la Administración" 38 .

No obstante y como ha afirmado el TEDH, el interés debe estar mínimamente personalizado para que del mismo emane el Derecho de acceso a la jurisdicción en favor de su titular $^{39}$. Este derecho, concretamente, se ha materializado en la práctica de los Tribunales en una interpretación de la normativa procesal a favor del inicio del proceso (principio pro actione) ${ }^{40}$. Este principio implica que deben evitarse los denominados "formalismos enervantes" 41 , entre otros posibles impedimentos en el acceso a la jurisdicción de los intereses apuntados ${ }^{42}$.

Por último y para desarrollar el contenido del derecho de acceso a la jurisdicción apuntado hasta ahora, se requiere una breve descripción de las dos teorías de la acción defendidas por los distintos autores en base al carácter de la acción ${ }^{43}$. En primer lugar, tenemos la teoría abstracta de la acción que trata a ésta como derecho a la actividad jurisdiccional. Por otro lado, la

\footnotetext{
${ }^{36}$ SSTC núm. 9/1981, de 31 de marzo, núm. 19/1981, de 11 de junio, núm. 11/1982, de 29 de marzo, núm. 19/1983, de 14 de marzo y núm. 68/1983, de 26 de julio.

${ }^{37}$ SSTC núm. 60/1982, de 11 de octubre, núm. 62/1983, de 11 de octubre, núm. 257/1988, de 22 de diciembre y núm. 97/1991, de 9 de mayo y ATC núm. 356/1989, de 29 de junio. Por parte del Tribunal Supremo cabe destacar las sentencias de 4 de marzo de 2003, 9 de marzo de 2005 y más recientemente, la sentencia de 22 mayo de 2007.

${ }^{38}$ STC núm. 195/1992, de 16 de noviembre, FJ $4^{\circ}$.

${ }^{39}$ STEDH Markovic y otros c. Italia de 14 de diciembre de 2006, relativa a una solicitud de indemnización que presentaron a las jurisdicciones italianas diez ciudadanos de la antigua Serbia y Montenegro por la muerte de personas a consecuencia de los bombardeos de la OTAN de abril de 1999, el Tribunal se declaró competente, porque a partir del momento en que se había formulado una acción civil ante aquellas jurisdicciones internas existía indiscutiblemente un vínculo de jurisdicción entre Italia y los demandantes en el sentido del artículo $1^{\circ}$ de la Convención. Con todo, el fallo fue de no violación porque la petición de los demandantes ante las jurisdicciones italianas se había tramitado conforme a las exigencias del juicio equitativo. Esta sentencia puede interpretarse en el sentido de que tratándose de la invocación del artículo $6^{\circ}$ de la Convención (derecho a un juicio equitativo), el Tribunal siempre tiene jurisdicción (PASTOR RIDRUEJO, J. A., La reciente jurisprudencia del Tribunal Europeo de Derechos Humanos: Temas escogidos, Cursos de Derecho internacional y Relaciones internacionales de VitoriaGazteiz, 2007: Vitoria-Gasteizko nazioarteko zuzenbide eta nazioarteko harremanen ikastaroak, 2007 / coord. por Francisco Javier Quel López, Juan José Alvarez Rubio, 2008, p. 271).

${ }^{40}$ BELLIDO PENADÉS, R., La protección de los consumidores en el proceso civil, en Revista General de Derecho Procesal, 23, 2011.p. 20. Véase también la siguiente jurisprudencia: SSTC núm. 36/1997, de 25 de febrero, F. 3; núm. 8/1998, de 13 de enero, F. 3; núm. 38/1998, de 17 de febrero, F. 2; núm. 63/1999, de 26 de abril, F. 2; núm. 157/1999, de 14 de septiembre, F. 2; núm. 10/2001, de 29 de enero, F. 4; núm. 16/2001, de 29 de enero, F. 4; núm. 203/2004, de 16 de noviembre, F. 2; núm. 44/2005, de 28 de febrero, F. 3; núm. 160/2001, de 5 de julio, F. 3; núm. 27/2003, de 10 de febrero, F. 4; núm. 177/2003, de 13 de octubre, F. 3; núm. 3/2004, de 14 de enero, F. 3; 79/2005, de 2 de abril, F. 2; núm. 133/2005, de 23 de mayo, F. 2; núm. 75/2008, de 23 de junio, F. 2; núm. 11/2009, de 12 enero; núm. 187/2009, de 7 septiembre y núm. 25/2010, de 27 abril, entre otras.
}

${ }^{41}$ DÍEZ-PICAZO, L.M., "La tutela judicial efectiva (1 $1^{\mathrm{a}}$ Parte)", Estudios y Comentarios Legislativos (Civitas), Aranzadi, Pamplona, 2008, p. 4.

42 SSTC núm. 206/1987, de 21 de diciembre, núm. 46/1989, de 21 de febrero, núm. 96/1992, de 11 de junio, núm. 159/1999, de 14 de septiembre, núm. 45/2002, de 25 de febrero, núm. 237/2005, de 26 de septiembre y núm. 227/2007, de 22 de octubre y SSTEDH Sáez Maeso c. España de 9 de enero de 2004 y Cañete Goñi c. España de 15 de octubre de 2002.

${ }^{43}$ MONTERO AROCA, J. y FLORES MATÍES, J., Amparo constitucional y proceso civil, Tirant lo Blanch, Valencia, 2008, dónde se analiza la STC 124/2002 que expone la distinta doctrina española al respecto.

Revista de Direito Brasileira | São Paulo, SP | v. 18 | n. 7 | p. 438 - 462 |Set./Dez. 2017 
teoría concreta de la acción considera a ésta última como la satisfacción de la solicitud promovida por el ciudadano cuando tenga derecho a su obtención ${ }^{44}$. Sin embargo, esta segunda teoría parte de dos premisas inexistentes en la práctica habitual: (1) el derecho es un producto perfecto y (2) siempre hay buena fe por parte de los litigantes. Junto con esto y de acuerdo con GARBERÍ LLOBREGAT, la teoría concreta de la acción no sirve para explicar la acción, resulta inaplicable al derecho penal e implicaría un conocimiento de antemano del desenlace del proceso, además de resultar incoercible, ya que se ejecutaría frente el Estado ${ }^{45}$.

Por todo lo apuntado, el Tribunal Constitucional ha elegido la teoría abstracta expansiva de la acción, ya que, más allá de entender la acción como el derecho de acceso a la jurisdicción, la concibe junto con la obtención de una resolución judicial dictada conforme a Derecho ${ }^{46}$.

En este sentido, el derecho de acceso a la jurisdicción es considerado el primero de los contenidos del derecho a la tutela judicial efectiva "en un orden lógico y cronológico" 47 , y de naturaleza constitucional, al nacer de la Ley Suprema ${ }^{48}$. Asimismo, su contenido principal es ser parte en un proceso para promover la actividad jurisdiccional que desembocará en una decisión judicial sobre las pretensiones deducidas ${ }^{49}$. En otras palabras, CORDON MORENO resume su

\footnotetext{
${ }^{44}$ Respecto a los autores de las respectivas teorías apuntadas, cabe destacar en cuanto a teorías concretas de la acción: ORTELLS RAMOS, M., Derecho jurisdiccional, Bosch, Barcelona, 1989, pp. 245-249; DE LA OLIVA, A., Derecho Procesal Civil, I, Centro de Estudios Ramón Areces, 1991, pp. 139; GÓMEZ ORBANEJA, E., Derecho Procesal Civil, Vol. Primero, edit. por el autor, Madrid, 1979, p. 227; PODETTI, J. R., Teoría y práctica del derecho Civil y Triología estructural de la Ciencia del Proceso Civil, Ediar, Buenos Aires, 1963, p. 383; WACH, A., Der Feststellungsanspruch. Ein Beitrag zur Lehre vom Rechtsschutznspruch, Duncker \& Humbolt, Leipzig, 1889; HELLWIG, K., Lebruch des deutschen Zivilprocessrechts, Scientia Verlag Aalen, Leipzig, 1980, pp. 379-400; CHIOVENDA, G., L'azione nel sistema dei diritti, en Saggi di diritto processuale civile, Società Editrice "Foro Italiano", 1930, pp. 3-99; y CALAMANDREI, P., Relatività del concetto di azione, en Istituzioni di Diritto Processuale Civile, I, CEDAM, Padova, 1994, pp. 104 y ss.). Por otro lado, las teorías abstractas de: MONTERO AROCA, En torno al concepto y contenido del derecho jurisdiccional, en Revista de Derecho Procesal Iberoamericana, 1976, p. 170; PLOSZ, Beiträge zur Theorie des Klagerechts, Leipzig, 1880, DEGENKOLB, H., Einlassungszway und ureilsnorm. Beiträge zur materiellen Theorie der Klagen insbesondere der Anerkennungskalgen, Scientia Verlag Aalen, Leipzig, 1969, pp. 4-55; FAZZALARI, E., "Processo" e giurisdizione, en Rivista di Diritto Processuale, 1993, p. 13 y ZANZUCCHI, M. T., Diritto Processuale Civile, I, $6^{\circ}$ ed., Giuffrè, Milano, 1964, pp. 56-61).

${ }^{45}$ GARBERÍ LLOBREGAT, J., El derecho a la tutela judicial efectiva en la jurisprudencia del Tribunal Constitucional, Bosch, Barcelona 2008, pp. 11-18 y 27-28.

En el mismo sentido, ORMAZABAL SÁNCHEZ, G., Introducción al Derecho Procesal, Marcial Pons, Madrid, 2013, pp. 117-125; DE LA OLIVA, A., Sobre el derecho a la tutela jurisdiccional. La persona ante la Administración de Justicia: derechos básicos, Bosch, Barcelona, 1980;. PICÓ i JUNOY, J., Las garantías constitucionales del proceso, Bosch, Barcelona, 2012, p. 69, GUASP, J., Derecho Procesal Civil, p. 215; ANGElOTTI, D., La pretesa giuridica, CEDAM, Padova, 1932, p. 44; ROMANO, S., Fragmentos de un diccionario jurídico, EJEA, Buenos Aires, 1964, p. 319; MICHELI, G. A., Curso de Derecho Procesal Civil, Vol. 1, Ediciones Jurídicas Europa-América, Buenos Aires, 1970, p. 20; LEVI, A., La certezza del diritto in rapporto con il concetto dei azione, en Scritti giuridici in onore di Francesco Carnelutti, Volume primo, CEDAM, Padova, 1950, p. 93. Destacar también el análisis de las SSTC núm. 20/1981, de 8 de junio y núm. 32/1982, de 7 de junio como jurisprudencial inicial en cuanto el derecho fundamental de acceso a la jurisdicción (LORCA NAVARRETE, J. F. y LORCA MARTÍN DE VILLODRES, M. I., Derechos fundamentales y jurisprudencia, Ediciones Pirámide, Madrid, $4^{\text {a }}$ Edición, 2010, pp. 454-455).

${ }^{46}$ SSTC núm. 52/1992, de 8 de abril y núm. 20/1987, de 19 de febrero, núm. 50/1997, de 11 de marzo, núm. 9/2005, de 17 de enero, núm. 308/2006, de 23 de octubre, núm. 132/2007, de 4 de junio y núm. 9/1981, de 31 de marzo, entre otras.

Esta concepción más amplia es producto de las objeciones a la teoría abstracta por resultar su contenido insuficiente como tutela judicial, tal y como recoge: SERRA DOMÍNGUEZ, M., Evolución histórica y orientaciones modernas del concepto de acción, en Revista de Derecho Procesal Iberoamericana, 1963, pp. 35-92 y GÓMEZ COLOMER, Reflexiones sobre las bases científicas de la parte general del Derecho Jurisdiccional, Justicia 89, n. ${ }^{\circ}$ III, p. 595.

${ }^{47}$ SSTC núm. 226/2006, de 17 de julio, núm. 330/2006, de 20 de noviembre, núm. 148/2007, de 18 de junio, núm. 251/2007, de 17 de diciembre, núm. 25/2008, de 11 de febrero y núm. 26/2008, de 11 de febrero, entre otras.

${ }^{48}$ ATC núm. 100/1996, de 24 de abril.

${ }^{49}$ SSTC núm. 251/2007, de 17 de diciembre y núm. 26/2008, de 11 de febrero
}

Revista de Direito Brasileira | São Paulo, SP | v. 18 | n. 7 | p. 438 - 462 | Set./Dez. 2017 
contenido como la ausencia de requisito formal alguno que pueda convertirse en un obstáculo que impida injustificadamente pronunciarse sobre el fondo ${ }^{50}$. En consecuencia, el contenido y significado del derecho de acceso a la jurisdicción se concreta en la obligación de proporcionar una tutela en un proceso y ante un órgano jurisdiccional en caso de afectación de cualquier situación jurídicamente relevante. De esta forma, nace la obligación por parte del Estado de llevar a cabo una determinada actuación para evitar cualquier forma de denegación de justicia ${ }^{51}$.

Por ende, y de acuerdo con los artículos 53.1 y 117 de la Constitución Española, se trata de un derecho frente al Estado que vincula al poder judicial en la interpretación de las normas jurídicas y al poder legislativo en el dictamen de normas impeditivas u obstaculizadoras que carezcan de razonabilidad o proporcionalidad respecto a los fines que lícitamente puede perseguir el legislador en el marco de la LEC $^{52}$. Es decir, toda limitación u obstáculo deberá obedecer a finalidades razonables de protección de bienes e intereses constitucionalmente protegidos y deberá guardar una notoria proporcionalidad con la carga de diligencia exigible a los justiciables ${ }^{53}$.

Dicho esto, el contenido del derecho de acceso a la jurisdicción ha sido desarrollado y ampliado por la jurisprudencia constitucional a partir de la llamada tutela judicial "efectiva" "54 . En virtud de la misma, el derecho de acceso a la jurisdicción no se limita a la inexistencia de restricciones, sino que se materializa también en la prohibición de indefensión ${ }^{55}$, en el derecho a una resolución de fondo y motivada, en el derecho de acceso a los recursos y en la intangibilidad de las resoluciones firmes ${ }^{56}$. Todo ello sin perjuicio de que el legislador pueda imponer determinadas obligaciones sin que representen éstas un menoscabo al derecho de acceso a la jurisdicción, tales como una obligación de intento de solución extrajudicial de un determinado conflicto o una presunción iuris tantum de sometimiento a un órgano arbitral ${ }^{57}$.

En este punto y para poder determinar si la tutela individual de los intereses pluriindividuales homogéneos puede conllevar la vulneración del derecho de acceso a la jurisdicción, es imprescindible analizar las particularidades fácticas existentes en este tipo de intereses.

Para lograr dicha finalidad, presentaré a continuación un supuesto de hecho extraído de la jurisprudencia española en el que se utilizó una acción colectiva para la tutela de daños pluriindividuales homogéneos, concretamente el que dio lugar a la Sentencia del Tribunal Supremo de 15 de julio de 2000. A partir del mismo, detallaré las circunstancias fácticas que presentan este tipo de intereses desde el punto de vista de la tutela judicial efectiva, con la

\footnotetext{
${ }^{50}$ CORDÓN MORENO, F., El derecho a obtener una tutela judicial efectiva en CGPJ, Manuales de formación continuada: derechos procesales fundamentales, 2005, pp. 217-219, citando las SSTC núm. 74/1983, de 30 de julio, núm. 26/1984, de 24 de febrero y núm. 57/1984, de 8 de mayo. De forma análoga, GIMENO SENDRA considera que han de resultar inconstitucionales los obstáculos jurídicos o económicos que puedan impedir o dificultar este libre acceso (GIMENO SENDRA, V., Derechos fundamentales y su protección, Colex, Madrid, 2007, p. 524.)

${ }^{51}$ DÍEZ-PICAZO, L.M., La tutela judicial efectiva (1 ${ }^{\mathrm{a}}$ Parte), Estudios y Comentarios Legislativos (Civitas), Editorial Aranzadi, Pamplona, 2008, p. 3.

${ }_{53}^{52}$ SSTC núm. 251/2007, de 17 de diciembre y núm. 26/2008, de 11 de febrero, entre otras.

${ }_{54}^{53}$ STC núm. 13/2008, de 31 de enero.

${ }^{54}$ El contenido de este derecho se analiza ampliamente en la monografía: GARBERÍ LLOBREGAT, J., El Derecho a la tutela, op. cit..

${ }^{55}$ Hay indefensión cuando falta posibilidad de contradicción (SSTC núm. 19/1984, de 10 de febrero, núm. 39/1987, de 3 de abril, núm. 36/1987, de 25 de marzo, núm. 41/1987, de 6 de abril).

${ }^{56}$ Por razones de concreción no se va a desarrollar cada uno de los puntos pero se encuentran recogidos, esencialmente, en las siguientes sentencias: prohibición de indefensión (SSTC núm. 101/2001, de 26 de abril y núm. 143/2001, de 18 de junio), el derecho a una resolución de fondo y motivada (SSTC núm. 128/2003, de 30 de junio, núm. 42/2004, de 23 de marzo y núm. 8/2004, de 9 de febrero), el derecho de acceso a los recursos (STC núm. 42/1982, de 5 de julio) y la intangibilidad de las resoluciones firmes (SSTC núm. 231/1991, de 10 de diciembre, núm. 179/1999, de 11 de octubre, núm. 176/2001, de 17 de septiembre, núm. 141/2003, de 14 de julio, núm. 190/2004, de 2 de noviembre y núm. 224/2004, de 29 de noviembre).

${ }^{57}$ STC núm. 352/2006, de 14 de diciembre.
}

Revista de Direito Brasileira | São Paulo, SP | v. 18 | n. 7 | p. 438 - 462 |Set./Dez. 2017 
finalidad de destacar todos aquellos elementos que obligan a adoptar un instrumento de tutela colectiva.

Para evitar la redundancia con lo ya expuesto en las líneas precedentes, simplemente señalaré los siguiente elementos fácticos del siguiente modo: a) el temporal de nueve produjo múltiples accidentes que obstruyeron la Autopista de Burgos a Armiñón; b) ante dichas circunstancias, no tan sólo no se alertó a los conductores de los mismos, sino que se permitió que fueran accediendo a la autopista a pesar del estado en que ésta se hallaba ${ }^{58}$; c) como consecuencia de ello, más de 6000 personas se quedaron atrapadas en la carretera o se vieron obligadas a pernoctar en polideportivos y centros diversos de las inmediaciones; d)cuando se restableció la circulación a lo largo de la mañana y el mediodía del día 28 de febrero, los vehículos que habían quedado atrapados tuvieron que pagar el correspondiente canon de peaje para poder abandonarla ${ }^{59}$.

A partir de esta situación, los afectados tenían la posibilidad de solicitar la tutela de sus intereses y derechos afectados ante los Tribunales, ya fuera individual o colectivamente a través de las organizaciones legitimadas para ello ${ }^{60}$. En el presente caso, una asociación de consumidores y usuarios (AUSBANC CONSUMO) ejerció una acción colectiva de los usuarios frente a la entidad concesionaria de la autopista en base al Artículo 10 de la Ley 1/2000, de Enjuiciamiento Civil $^{61}$.

La elección de la tutela colectiva no es baladí, sino que en este supuesto responde claramente a la característica fáctica principal de las acciones colectivas. Es decir, la desproporción entre la cuantificación del daño de los intereses afectados y las costas procesales y tasas judiciales obligan a que los daños sean tratados en un mismo proceso, ya que si los afectados hubieran optado por una tutela individual, cada uno de ellos hubiera tenido que afrontar un riesgo económico muy superior para obtener una indemnización económicamente ínfima. En cambio, la tutela colectiva permite la sustantación en un solo proceso de los daños producidos a la totalidad de afectados. Por ende, me atrevo a afirmar que ante la ausencia de un sistema de tutela colectiva, serían muy pocos los afectados que ejercitarían acciones individuales para la tutela de los intereses afectados ante los Tribunales, ya que el desequilibrio económico los disuadiría de ejercer la acción individual ${ }^{62}$.

Con el objetivo de reafirmar esta posición, procedo a analizar la jurisprudencia en cuanto al derecho de acceso a la jurisdicción. Si bien correspondería a los tribunales nacionales interpretar las reglas internas de naturaleza procesal, resulta más idónea la jurisprudencia emanada del Tribunal Europeo de Derecho Humanos ${ }^{63}$, ya que este Tribunal se ha convertido en el referente actual en cuanto a derechos fundamentales, como órgano de interpretación y aplicación del Convenio Europeo de Derechos Humanos ${ }^{64}$. El objetivo, por consiguiente, es

\footnotetext{
${ }^{58}$ SAP de Burgos núm. 347/2006, de 31 julio.

${ }^{59}$ Para un análisis de la Sentencia del Tribunal Supremo núm. 473/2010, de 15 de julio de 2010 ver GASCÓN INCHAUSTI, F., Acción, op. cit..

${ }^{60}$ De hecho, en la actualidad y partir de la modificación hecha por la Ley de Consumidores y Usuarios de 27 de marzo de 2014, también estaría legitimado el Ministerio Fiscal, ya que se trata de un supuesto en el que los afectados no eran determinables (art. 11.3 LEC).

${ }^{61}$ STS núm. 473/2010, de 15 de julio de 2010.

${ }^{62}$ SJPI núm. 45 de Madrid, núm. 234/2003, de 24 noviembre.

${ }^{63}$ Tribunal Europeo de Derechos Humanos, Sentencia Tejedor García contra España de 16 diciembre 1997, Repertorio de sentencias y decisiones 1997-VIII, pg. 2796, ap. 31.

${ }^{64}$ JIMENA QUESADA, L, Sistema Europeo de Derechos Fundamentales, Colex, Madrid, 2006, p. 63. En cuanto a la efectividad y aplicación de las sentencias dictadas por el Tribunal Europeo de Derechos Humanos en el caso del estado Español: GARRIGA DOMÍNGUEZ, A (Directora), "La controvertida eficacia directa de las sentencias del Tribunal Europeo de Derechos Humanos: apuntes sobre el alcance de la violación del derecho a un proceso equitativo contemplado en el artículo 6.1 del CEDH y las limitadas posibilidades de su restitución plena en el proceso español en relación con los recientes pronunciamientos del Tribunal Constitucional", El tiempo de los derechos, núm. 12, 2010.
}

Revista de Direito Brasileira | São Paulo, SP | v. 18 | n. 7 | p. 438 - 462 | Set./Dez. 2017 
hallar argumentos en la jurisprudencia del TEDH que justifiquen la vulneración del derecho de acceso a la jurisdicción como consecuencia del grave desequilibrio económico entre los gastos para obtener la tutela individual y la posible indemnización a percibir en caso que se estime la pretensión.

Veamos en primer lugar, cual es el concepto del derecho fundamental de acceso a la jurisdicción se contempla en el artículo 6.1 del CEDH, ya que a partir de su contenido podremos determinar si la acción individual es suficiente para la tutela de los intereses pluriindividuales homogéneos $^{65}$. El TEDH ha establecido que el artículo 6.1 garantiza a cada uno el derecho a que un Tribunal conozca cualquier litigio relativo a sus derechos y obligaciones de carácter civil $^{66}$. De este modo, el derecho de acceso a la jurisdicción requiere que exista (a) un derecho u obligación de carácter civil en el ordenamiento jurídico del Estado en cuestión y, constatada la existencia del mismo, es cuando nace (b) la obligación del Estado de tutelar dicho derecho u obligación en concreto.

En cuanto a la existencia de un derecho u obligación de carácter civil reconocido en la legislación interna, el TEDH afirma que no puede crearse un derecho sustantivo que carezca de base legal en el Estado en cuestión ${ }^{67}$, ya que las garantías del artículo 6.1 del CEDH se extienden únicamente a los derechos que estén previamente reconocidos en la legislación interna ${ }^{68}$. En consecuencia, el punto de partida para considerar la existencia de un determinado derecho serán las disposiciones de la legislación interna y la interpretación de las mismas hechas por los tribunales internos ${ }^{69}$.

Respecto a la obligación por parte del Estado de tutelar el derecho u obligación reconocidos en su ordenamiento jurídico, el grado de acceso procurado por la legislación nacional ha de ser suficiente para asegurar al individuo el «derecho a un Tribunal», como parte del principio de la preminencia del derecho en una sociedad democrática. En este sentido, la afectación de un derecho o interés protegido por el ordenamiento jurídico no podrá quedar sin la tutela judicial respectiva ${ }^{70}$.

Volviendo ahora en el supuesto de hecho descrito anteriormente, cabe ver si podemos afirmar que, en el caso español, se cumplen los dos requisitos desarrollados y establecidos por la jurisprudencia del Tribunal Europeo de Derechos Humanos para considerar garantizado el derecho de acceso a la jurisdicción. La respuesta es afirmativa: en primer lugar, los derechos o intereses de los consumidores y usuarios están reconocidos en la legislación interna (Ley General

\footnotetext{
65 "Toda persona tiene derecho a que su causa sea oída equitativa, públicamente y dentro de un plazo razonable, por un Tribunal independiente e imparcial, establecido por ley, que decidirá los litigios sobre sus derechos y obligaciones de carácter civil o sobre el fundamento de cualquier acusación en materia penal dirigida contra ella. La sentencia debe ser pronunciada públicamente, pero el acceso a la sala de audiencia puede ser prohibido a la prensa y al público durante la totalidad o parte del proceso en interés de la moralidad, del orden público o de la seguridad nacional en una sociedad democrática, cuando los intereses de los menores o la protección de la vida privada de las partes en el proceso así lo exijan o en la medida en que sea considerado estrictamente necesario por el tribunal, cuando en circunstancias especiales la publicidad pudiera ser perjudicial para los intereses de la justicia."

${ }^{66}$ Tribunal Europeo de Derechos Humanos, Caso Golder contra Reino Unido, Sentencia de 21 febrero 1975.

${ }^{67}$ Tribunal Europeo de Derechos Humanos, Caso Fayed contra Reino Unido, Sentencia de 21 septiembre 1994, ap. 65.

${ }^{68}$ Tribunal Europeo de Derechos Humanos, Casos James y otros contra Reino Unido, Sentencia de 21 febrero 1986, series A núm. 98 y Z y otros, a p. 81, y las referencias que contienen, junto con McElhinney contra Irlanda [GS], núm. 31253/1996, ap. 23, Sentencia de 21 noviembre 2001; y Fogarty contra Reino Unido [GS], Sentencia núm. 37112/1997, ap. 117, TEDH 2001-XI.

69 Tribunal Europeo de Derechos Humanos, Caso Masson y Van Zon contra Países Bajos, Sentencia de 28 septiembre 1995, serie A núm. 327-A, p. 19, ap. 49).

${ }^{70}$ Tribunal Europeo de Derechos Humanos, Caso F.E. contra Francia, Sentencia de 30 octubre 1998, Repertorio de sentencias y decisiones 1998-VIII, pg.- 3349, ap. 44, y Caso Yagtzilar y otros contra Grecia, Sentencia núm. 41727/1998, a p. 23, CEDH 2001-XII.
}

Revista de Direito Brasileira | São Paulo, SP | v. 18 | n. 7 | p. 438 - 462 |Set./Dez. 2017 
para la Defensa de los Consumidores y Usuarios ${ }^{71}$ ) y, por otro lado, los consumidores o usuarios cuyos intereses se hubieran lesionado están legitimados para exigir la tutela de los mismos en la jurisdicción civil, en virtud del artículo 10 de la Ley de Enjuiciamiento Civil. Consiguientemente, el derecho de acceso a la jurisdicción parece estar garantizado.

No obstante, cabe ir más allá y determinar si las particularidades fácticas de los intereses pluriindividuales homogéneos apuntadas requieren de las acciones colectivas como tutela para que dicha garantía constitucional sea efectiva, cosa que me dispongo a hacer en las líneas que siguen. En particular, dicho acceso individual no parece suficiente por la poca cuantía de la afectación en los daños masivos. Por esta misma razón, ponderaré el desequilibrio económico entre los gastos de litigación, junto con las tasas judiciales, y la indemnización a percibir por los afectados con la finalidad de determinar si la tutela individual de los derechos e intereses de los consumidores afectados sería suficiente para garantizar el derecho de acceso a la jurisdicción de los mismos.

La clave interpretativa para dicha ponderación reside en la efectividad del derecho de acceso a la jurisdicción ${ }^{72}$. El TEDH establece que únicamente se considerará efectivo el derecho de acceso a la jurisdicción si el individuo disfruta de una posibilidad clara y concreta para discutir un acto que constituye una injerencia en sus derechos ${ }^{73}$ ). En caso contrario, "quien, considerando ilegal una injerencia en el ejercicio de uno de sus derechos (de carácter civil) podrá quejarse de no haber tenido la ocasión de presentar una demanda ante un tribunal que responda a las exigencias del artículo 6.1»",74.

A tenor de lo apuntado, es preciso mencionar también los Casos Aït-Mouhoub contra Francia $^{75}$ y Airey contra Irlanda para realizar dicha ponderación ${ }^{76}$. En ambos casos, el TEDH se enfrenta a situaciones en las que los demandantes ven impedido su acceso a la jurisdicción por razones económicas. En el primer caso, la imposibilidad de pago de un depósito impide al demandante proseguir con el proceso, mientras que, en el segundo, el impedimento es el alto coste del proceso ante el único órgano legitimado en la materia. Según el TEDH, existe una violación del artículo 6.1 del CEDH de un modo fáctico tanto en el primero como en el segundo caso apuntado, ya que un impedimento fáctico puede violar el CEDH tanto como uno jurídico (la ya citada Sentencia Golder). Enfatiza, además, que el CEDH obliga al Estado a llevar a cabo acciones positivas para garantizar el acceso a la jurisdicción, establece que la inactividad del Estado ante un impedimento de acceso a la jurisdicción por razones económicas se convierte en una vulneración del derecho fundamental de acceso a la jurisdicción de las personas cuyos intereses legalmente reconocidos se han visto afectados ${ }^{77}$.

\footnotetext{
${ }^{71}$ Real Decreto Legislativo 1/2007, de 16 de noviembre, por el que se aprueba el texto refundido de la Ley General para la Defensa de los Consumidores y Usuarios y otras leyes complementarias.

${ }^{72}$ El Convenio perseguía la protección de los derechos considerados no en sentido teórico o ideal, sino como derechos reales y efectivos (ver, "mutatis mutandis", el caso del "régimen lingüístico en Bélgica", el anteriormente citado Golder, el de Luedicke, Belkacem y Koq y el de Marckx). Esto es singularmente claro en relación con el derecho de acceso a los Tribunales a la vista del papel preeminente que en una sociedad democrática tiene el derecho a un juicio justo (Caso Delcourt).

${ }^{73}$ Tribunal Europeo de Derechos Humanos, Caso Bellet contra Francia, Sentencia de 4 diciembre 1995, serie A núm. 333-B, p. 42, ap. 36 y Caso Cañete de Goñi contra España, Sentencia de 15 octubre 2002.

${ }^{74}$ Tribunal Europeo de Derechos Humanos, Casos Le Compte, Van Leuven y De Meyere contra Bélgica, Sentencia de 23 junio 1981, serie A núm. 43, pg. 20, ap. 44, y Les Saints Monasteres contra Grecia, Sentencia de 9 diciembre 1994, serie A núm. 301-1, pp. 36-37, ap. 80.

${ }^{75}$ Tribunal Europeo de Derechos Humanos, Caso Ait-Mouhoub contra Francia, Sentencia de 28 octubre 1998.

${ }^{76}$ Tribunal Europeo de Derechos Humanos, Caso Airey contra Irlanda, Sentencia de 6 febrero 1981.

77 "No hay lugar a distinguir entre actos y omisiones (...)" Tribunal Europeo de Derechos Humanos, Sentencia Marckx, p. 15, a p. 31, y la De Wilde, Versyp de 10 marzo 1972, serie A, núm. 15, p. 10, a p. 22.
}

Revista de Direito Brasileira | São Paulo, SP | v. 18 | n. 7 | p. 438 - 462 | Set./Dez. 2017 


\section{CONCLUSIONES}

Una vez analizada toda la jurisprudencia del TEDH en esta materia, cabe dirimir si es aplicable al ordenamiento jurídico español. Conviene recordar, al respecto, que España ratificó el CEDH el 4 de octubre de 1979 y el propio artículo 10.2 CE establece que las normas relativas a los derechos y libertades fundamentales que la Constitución Española reconoce, se interpretarán de conformidad con el Derecho internacional de los derechos humanos vigente ${ }^{78}$. En este sentido, el TEDH ha establecido que el CEDH es considerado orden público europeo y la jurisprudencia emanada del mismo al respecto, parte integrante del CEDH. Tal y como apunta RIPOLL CARULLA y BUJOSA VADELL, entonces, el carácter jurídicamente obligatorio de la jurisprudencia del TEDH se amplía erga omnes, esto es, a todos los Estados parte ${ }^{79}$. Además, el propio Tribunal Constitucional en la STC 303/1993 estableció que de acuerdo con el artículo 10.2 de la CE, la jurisprudencia del Tribunal Europeo de Derechos Humanos (...), no sólo ha de servir de criterio interpretativo en la aplicación de los preceptos constitucionales tuteladores de los derechos fundamentales sino que también resulta de aplicación inmediata en nuestro ordenamiento $^{80}$. De acuerdo con esto, el Tribunal Constitucional español ha asumido mayormente los criterios establecidos por el $\mathrm{TEDH}^{81}$. En materia de consumidores y usuarios, concretamente, el Tribunal Constitucional ha recogido la doctrina Golder $^{82}$ y Airey ${ }^{83}$, sentencias pilares de la argumentación desarrollada hasta este punto.

Por ende, cabe concluir que el desequilibrio económico que conllevaría la tutela individual de esta tipología de daños puede impedir el acceso a los Tribunales para pedir la protección de los derechos subjetivos o intereses legítimos afectados ${ }^{84}$. En otros términos, si bien existiría una tutela individual del daño producido, dicha desproporción apuntada constituiría un impedimento económico-fáctico contrario al derecho de acceso a la jurisdicción contemplado en el artículo 6.1 del CEDH y en el 24.1 de la CE.

\footnotetext{
${ }^{78}$ Boletín Oficial del Estado, núm. 243 de 10 de octubre de 1979, pp. 23564 a 23570 (7 pp.).

${ }^{79}$ Cabe destacar la totalidad de la obra monográfica: BUJOSA VADELL, L.M., Las sentencias del Tribunal Europeo de Derechos Humanos y el ordenamiento español, Tecnos, 1997.

El llamado efecto de cosa interpretada de las sentencias del TEDH (RIPOLL CARULLA, S., Incidencia en la jurisprudencia del TC de las sentencias del TEDH que declaran la vulneración por España del CEDH, en Revista Española de Derecho Constitucional, núm. 79, enero-abril (2007), pág. 311). En el mismo sentido: Irlanda c. Reino Unido. STEDH de 18 de enero de 1978, párrafos 154 y 155. Asimismo, Rec (2004) 6 del Comité de Ministros sobre la mejora de los recursos internos, de 12 de mayo de 2005 . Anexo, punto 7.

${ }^{80}$ STC 303/1993, de 25 de octubre, FJ. 8. Además, dicha afirmación se manifestó con toda su amplitud en la Sentencia Bultó (STC núm. 245/1991 de 16 diciembre). Sin embargo, con la jurisprudencia posterior se fue matizando y con ello limitando dicha aplicación directa hasta tal punto de considerar el caso Bultó una mera solución excepcional ad hoc. (Ver: GARRIGA DOMÍNGUEZ, A (Directora), "La controvertida eficacia directa de las sentencias del Tribunal Europeo de Derechos Humanos: apuntes sobre el alcance de la violación del derecho a un proceso equitativo contemplado en el artículo 6.1 del CEDH y las limitadas posibilidades de su restitución plena en el proceso español en relación con los recientes pronunciamientos del Tribunal Constitucional", El tiempo de los derechos, núm. 12, 2010.

${ }^{81}$ Para un estudio de dicha incorporación: APARICIO, M. A., La cláusula interpretativa del art. 102 de la CE como cláusula de integración y apertura constitucional de los derechos fundamentales, en Jueces para la Democracia, núm. 6, 1989, pp. 9-18; DELGADO BARRIOS, J, Proyección de las decisiones del TEDH en la jurisprudencia española, en RAP, núm. 119, 1989, pp. 233-254; GARCÍA DE ENTERRÍA, E., El valor en derecho español de la jurisprudencia del TEDH, en Boletín informativo del Iltre. Colegio de Abogados de Madrid, núm. 1, 1987, p. 9; PÉREZ TREMS, P., Artículo 41, en REQUEJO PAGÉS, J. L. (coord.): Comentarios a la Ley Orgánica del Tribunal Constitucional, Madrid: Tribunal Constitucional/ BOE. 2001, pp. 633-655 (en particular. pp. 639-642); SAIZ ARNÁIZ. A., La apertura constitucional al derecho internacional y europeo de los derechos humanos: el artículo 10.2 de la constitución española, Consejo General del Poder Judicial, Madrid, 1999, pp. 321-342.

${ }^{82}$ STC núm. 140/1995, de 28 septiembre.

${ }^{83}$ STC núm. 105/1999, de 14 junio.

${ }^{84}$ SJPI núm. 45 de Madrid, núm. 234/2003, de 24 noviembre.
}

Revista de Direito Brasileira | São Paulo, SP | v. 18 | n. 7 | p. 438 - 462 |Set./Dez. 2017 
Me gustaría acabar el presente trabajo de investigación argumentando si las acciones colectivas es, como acabamos de ver, la única forma de eliminar la barrera económica que representa la desproporción descrita. Una solución posible sería el incremento del tanto indemnizatorio. Sin embargo, en el ordenamiento jurídico español, las reglas sobre responsabilidad civil obedecen a una finalidad reparadora del daño y, en este sentido, las acciones colectivas en materia de consumidores y usuarios se caracterizan por la poca entidad del mismo. Cabrían, asimismo, dos alternativas para eliminar la barrera o impedimento económico de acceso a la jurisdicción: la eliminación de las costas procesales y tasas judiciales o el reconocimiento de la acumulación de dichas cuantías individuales en un solo proceso, descartando la vía litisconsorcial para los daños masivos por la falta de adecuación de la figura para la tutela de daños tan extensos. Al respecto, la eliminación de las costas procesales y tasas judiciales es inviable para el sistema judicial español, ya que en 2010 las tasas judiciales recaudadas en España representaban un 4,1 \% del presupuesto de la Administración de Justicia, incluyendo en él las partidas destinadas a justicia gratuita y al Ministerio Fiscal, siendo inferiores a la mayoría de Estados Europeos ${ }^{85}$.

Por esta misma razón, las acciones colectivas se postulan como la única solución, ya que permiten la sustanciación de la pluralidad de daños a través de un solo procedimiento y desaparece, de este modo, el impedimento económico en el acceso a la jurisdicción de los intereses afectados ${ }^{86}$.

En suma, el fundamento de las acciones colectivas es la garantía del derecho de acceso a la jurisdicción del artículo 24 de la CE, junto una razón de índole económica procesal como es la concentración en un solo litigio de todos los afectados por la actividad empresarial dañosa, lo que favorece a la reducción de costes para la administración de justicia ${ }^{87}$.

\footnotetext{
${ }^{85}$ THE EUROPEAN COMMISSION FOR THE EFFICIENCY OF JUSTICE, Evaluation of European Judicial Systems, 2012.

${ }^{86}$ PLANCHADELl GARGALLO, A., Las "acciones colectivas" en el ordenamiento jurídico español. Un estudio comparado, Tirant lo Blanch, Valencia, 2014, p. 39; GUTIÉRREZ DE CABIEDES, La tutela jurisdiccional, op. cit., pp. 121 y ss.; GASCÓN INCHAUSTI, F., La protección de los consumidores en el proceso civil español, Institut André Tunc, Université Paris I-Pantheon Sorbone, Paris, 2005, pp. 2 y ss.; GONZÁLEZ GRANDA, P., La tutela de la pretensión colectiva de cesación en defensa de los intereses colectivos y difusos de consumidores y usuarios en el proceso civil, en AA VV, Homenaje a D. Eduardo Font Serra, Ministerio de Justicia, Centro de Estudios Jurídicos, Madrid, 2004, p. 635; BARONA VILAR, S., Acciones de cesación, retractación y declarativa, en BERCOVITZ RODRÍGUEZ-CANO, R, Comentarios a la Ley General para la Defensa de Consumidores y Usuarios, Aranzadi, 2000, p. 663; GOMEZ DE LIAÑO GONZÁLEZ, F. y GÓMEZ DE LIAÑO DIEGO, R., Ley de Enjuiciamiento Civil: Notas y Doctrina de Tribunales, Aranzadi, Pamplona, 2008, p. 158; ROSICÓ FAIRÉN, A., Notas sobre las acciones colectivas de consumo, en MONTOYA MELGAR, A., Cuestiones actuales de la jurisdicción en España, Dykinson, Madrid, 2010, p. 663; MÉNDEZ PINEDO, E., La protección de consumidores en la Unión Europea. Hacia un verdadero derecho procesal comunitario de consumo, Marcial Pons, Madrid, 1998, pp. 146 y ss.; GUISSANI, A., Azione collettive resarcitoria en el processo civil, Il Mulino, Bologna, 2009, pp. 29 y ss.

${ }^{87}$ AAP de Madrid núm. 265/2005, de 11 noviembre.
}

Revista de Direito Brasileira | São Paulo, SP | v. 18 | n. 7 | p. 438 - 462 | Set./Dez. 2017 


\section{BIBLIOGRAFÍA}

ANGELOTTI, D., La pretesa giuridica, CEDAM, Padova, 1932.

APARICIO, M. A., La cláusula interpretativa del art. 102 de la CE como cláusula de integración y apertura constitucional de los derechos fundamentales, en Jueces para la Democracia, núm. 6, 1989.

BARONA VILAR, S., Acciones de cesación, retractación y declarativa, en BERCOVITZ RODRÍGUEZ-CANO, R, Comentarios a la Ley General para la Defensa de Consumidores y Usuarios, Aranzadi, 2000.

BECEÑA, F., Magistratura y justicia, Madrid, 1928, Notas de derecho procesal civil, Madrid, 1932 ,

BELLIDO PENADÉS, R., La protección de los consumidores en el proceso civil, en Revista General de Derecho Procesal, 23, 2011.

BUJOSA VADELL, L.M., Las sentencias del Tribunal Europeo de Derechos Humanos y el ordenamiento español, Tecnos, 1997.

BULOW (BULOW, La teoría de las excepciones procesales y de los presupuestos procesales, Ediciones Jurídicas Europa América, Buenos Aires, 1964.

BUSTOS LAGO, J. M., Incumplimiento de la prestación de servicios financiada a través de un contrato de préstamo al consumo. Algunas precisiones a propósito del caso "Opening English School", en Actualidad Jurídica Aranzadi, núm. 564.

CABAÑAS GARCÍA diferencia entre derecho subjetivo, interés legítimo, interés colectivo e interés público en: La tutela judicial del tercero, Dijusa, Madrid, 2005.

CAJARBILlE PELUFFO, J. P., Conceptos constitucionales definitorios de la legitimación del actor relaciones entre derecho subjetivo, interés legítimo e interés general, Conferencia Magistral dictada por el autor en las VII Jornadas Académicas del Tribunal de lo Contencioso Administrativo, con la Co-Dirección de la Procuraduría del Estado en lo Contencioso Administrativo, celebradas los días 5 y 6 de noviembre de 2012).

CALAMANDREI, P., Opere Giuridiche, Morano, Nápoles, 1968.

- La certezza del diritto e la responsabilità della dottrina, en Opere giuridiche, I, Napoli, 1965CAPPELlETTI, M., Access to justice, Promising institutions, Alphennaandenrijn, Sijthoff and Noordhoff, Giuffrè, Milan, 1978-1979, Vol. II, Libro I.

- Relatività del concetto di azione, en Istituzioni di Diritto Processuale Civile, I, CEDAM, Padova, 1994.

CARBALlO PIÑEIRO, L., Protección de inversores, acciones colectivas y derecho internacional privado, en Revista de Derecho de Sociedades, 37/2011, Tomo 2.

CHAYES, The Role of the Judge in Public Law Litigation, en HARVARD LAW REVIEW, 89, 1976. 
CHIOVENDA, G., L'azione nel sistema dei diritti, en Saggi di Diritto Processuale Civile (19001930), Volume Primo, Società editrice "Foro Italiano", Roma, 1930.

- Istituzioni di Diritto Processuale Civile, Volume I, Casa editrice Dott. Eugenio Jovene, Napoli, 1960.

- $\quad$ Principii de Diritto Processuale Civile, Casa editrice Dott. Eugenio Jovene, Napoli, 1965.

CORDON MORENO, F., La legitimación en el proceso contencioso administrativo, EUN-SA, Pamplona, 1979.

- El derecho a obtener una tutela judicial efectiva en CGPJ, Manuales de formación continuada: derechos procesales fundamentales, 2005.

DE LA OLIVA, A., DIEZ-PICAZO, I., VEGAS TORRES, J., Curso de derecho procesal civil, Editorial Universitaria Ramón Areces, Madrid, 2012.

- Sobre el derecho a la tutela jurisdiccional. La persona ante la Administración de Justicia: derechos básicos, Bosch, Barcelona, 1980.

DELGADO BARRIOS, J, Proyección de las decisiones del TEDH en la jurisprudencia española, en RAP, núm. 119, 1989.

DEGENKOLB, H., Einlassungszway und ureilsnorm. Beiträge zur materiellen Theorie der Klagen insbesondere der Anerkennungskalgen, Scientia Verlag Aalen, Leipzig, 1969.

DEMOLOMBE, Ciurs de Code Napoleon, tomo IX, 4ºd., París, 1870, núm. 338.

DÍEZ-PICAZO, L.M., La tutela judicial efectiva ( $1^{\text {a }}$ Parte), Estudios y Comentarios Legislativos (Civitas), Editorial Aranzadi, Pamplona, 2008.

FAIREN GUILLÉN, V., Doctrina general de Derecho procesal, Bosch, Barcelona, 1990.

FAZZALARI, E., “Processo” e giurisdizione, en Rivista di Diritto Processuale, 1993.

GARBERÍ LLOBREGAT, J., El derecho a la tutela judicial efectiva en la jurisprudencia del Tribunal Constitucional, Bosch, Barcelona, 2008.

GARCÍA DE ENTERRÍA, E., El valor en derecho español de la jurisprudencia del TEDH, en Boletín informativo del Iltre. Colegio de Abogados de Madrid, núm. 1, 1987.

GARCIA SOBRECASES, F., Elección colectiva y provisión de bienes públicos [Microforma]: búsqueda de las soluciones al comportamiento free rider, Universitat de Valencia, Valencia, 1998.

GARCÍA VILA, M., Las condiciones generales de la contratación: aspectos procesales, Valencia, 2006. 
GARRIGA DOMÍNGUEZ, A (Directora), "La controvertida eficacia directa de las sentencias del Tribunal Europeo de Derechos Humanos: apuntes sobre el alcance de la violación del derecho a un proceso equitativo contemplado en el artículo 6.1 del CEDH y las limitadas posibilidades de su restitución plena en el proceso español en relación con los recientes pronunciamientos del Tribunal Constitucional", El tiempo de los derechos, núm. 12, 2010.

GASCÓN INCHAUSTI, F., La protección de los consumidores en el proceso civil español, Institut André Tunc, Université Paris I-Pantheon Sorbone, Paris, 2005.

- Acción colectiva de los usuarios frente a la entidad concesionaria de una autopista como consecuencia de las retenciones provocadas por una nevada (algunas consideraciones a la luz de la Sentencia del Tribunal Supremo de 15 de julio de 2010), en Aranzadi CivilMercantil, núm. 6/2011 (Estudio).

GIMENO SENDRA, V., Derechos fundamentales y su protección, Colex, Madrid, 2007.

GÓMEZ COLOMER, Reflexiones sobre las bases científicas de la parte general del Derecho Jurisdiccional, Justicia 89 , n. ${ }^{\circ}$ III.

GOMEZ DE LIAÑO GONZÁLEZ, F. y GÓMEZ DE LIAÑO DIEGO, R., Ley de Enjuiciamiento Civil: Notas y Doctrina de Tribunales, Aranzadi, Pamplona, 2008.

GÓMEZ ORBANEJA, E., El ejercicio de los derechos, Cuadernos Civitas, Madrid, 1975.

- Derecho Procesal Civil, Vol. Primero, edit. por el autor, Madrid, 1979.

GONZÁLEZ GRANDA, P., La tutela de la pretensión colectiva de cesación en defensa de los intereses colectivos y difusos de consumidores y usuarios en el proceso civil, en AA VV, Homenaje a D. Eduardo Font Serra, Ministerio de Justicia, Centro de Estudios Jurídicos, Madrid, 2004.

GUASP, J., Derecho Procesal Civil, Civitas, Madrid, 2003.

GUISSANI, A., Azione collettive resarcitoria en el processo civil, Il Mulino, Bologna, 2009.

GUTIEREZ-ALVIZ y CONRADI, Doctrina procesal español sobre la acción: 1830-1930, en Revista de Derecho Procesal Iberoamericana, 1979, 1.

GUTIÉRRREZ DE CABIEDES E HIDALGO DE CABIEDES, P., La Tutela Jurisdiccional de los Intereses Supraindividuales: Colectivos y Difusos, Elcano (Navarra), 1999.

HELLWIG, K., Lebruch des deutschen Zivilprocessrechts, Scientia Verlag Aalen, Leipzig, 1980.

JIMENA QUESADA, L, Sistema Europeo de Derechos Fundamentales, Colex, Madrid, 2006.

LEVI, A., La certezza del diritto in rapporto con il concetto dei azione, en Scritti giuridici in onore di Francesco Carnelutti, Volume primo, CEDAM, Padova, 1950.

LÓPEZ JIMÉNEZ, R., Comentarios prácticos a la LEC. Arts. 12 y 420, en Indret: Revista para el Análisis del Derecho, ISSN-e 1698-739X, Nº. 4, 2004. 
LORCA NAVARRETE, J. F. y LORCA MARTÍN DE VILLODRES, M. I., Derechos fundamentales y jurisprudencia, Ediciones Pirámide, Madrid, 4ª Edición, 2010.

LLAMAS POMBO, E., «Caso Opening», sentido común y sentido jurídico en Práctica de Derecho de Daños, № 39, Sección Editorial, Junio 2006.

- Requisitos de la acción colectiva de responsabilidad civil, en Diario La Ley, núm. 7141, 24 de marzo de 2009.

- Reflexiones sobre derecho de daños: casos y opiniones, La Ley, Madrid, 2010.

MÉNDEZ PINEDO, E., La protección de consumidores en la Unión Europea. Hacia un verdadero derecho procesal comunitario de consumo, Marcial Pons, Madrid, 1998.

MICHELI, G. A., Curso de Derecho Procesal Civil, Vol. 1, Ediciones Jurídicas Europa-América, Buenos Aires, 1970.

MONACCIANI, L., Diritto Processuale Civile, I, Giuffrè, Milano, 1964

MONTERO AROCA, J., En torno al concepto y contenido del derecho jurisdiccional, en Revista de Derecho Procesal Iberoamericana, 1976.

- Introducción al Derecho Procesal. Jurisdicción, acción y proceso, Tecnos, Madrid, 1979.

- Aproximación a la biografía de Francisco Beceña, en Estudios de Derecho Procesal, Barcelona, 1981.

- El proceso no tiene naturaleza jurídica, en Revista de Derecho Procesal, 1, 1990

- La legitimación colectiva de las entidades de gestión de la propiedad intelectual, Comares, Granada, 1997.

- Amparo constitucional y proceso civil, Tirant lo Blanch, Valencia, 2008.

- Con GOMEZ COLOMER, J. L., MONTÓN REDONDO, A. y BARONA VILAR, S., Derecho jurisdiccional II: Proceso civil, Tirant lo Blanch, Valencia, 2011.

MORÓN PALOMINO, M., Derecho Procesal Civil (Cuestiones fundamentales), Marcial Pons, Madrid, 1993.

MUTHER, Sobre la doctrina de la "actio" romana, del actual derecho de acción, de la "litiscontestatio” y de la sucesión singular en las obligaciones, Erangen, 1857.

OLSON, The logic of Collective Action, Harvard University Press, Cambridge, 2002.

OROMÍ VALL-LLOVERA, S., Intervención de terceros en el proceso civil: facultades procesales del interviniente, Marcial Pons, Madrid, 2007.

ORTELLS RAMOS, M., Derecho jurisdiccional, Bosch, Barcelona, 1989. 
PEKELIS, Azione en Nuovo Digesto Italiano, vol. II, Torino, 1938.

PÉREZ TREMS, P., Artículo 41, en REQUEJO PAGÉS, J. L. (coord.): Comentarios a la Ley Orgánica del Tribunal Constitucional, Madrid: Tribunal Constitucional/ BOE, 2001.

PICÓ i JUNOY, J., Las garantías constitucionales del proceso, Bosch, Barcelona, 2012.

PLANCHADELL GARGALLO, A., Las “acciones colectivas” en el ordenamiento jurídico español. Un estudio comparado, Tirant lo Blanch, Valencia, 2014.

PODETTI, J. R., Teoría y práctica del derecho Civil y Triología estructural de la Ciencia del Proceso Civil, Ediar, Buenos Aires, 1963.

PLOSZ, Beiträge zur Theorie des Klagerechts, Leipzig, 1880.

RIPOLL CARULLA, S., Incidencia en la jurisprudencia del TC de las sentencias del TEDH que declaran la vulneración por España del CEDH, en Revista Española de Derecho Constitucional, núm. 79, enero-abril (2007).

ROMANO, S., Fragmentos de un diccionario jurídico, EJEA, Buenos Aires, 1964.

ROSICÓ FAIRÉN, A., Notas sobre las acciones colectivas de consumo, en MONTOYA MELGAR, A., Cuestiones actuales de la jurisdicción en España, Dykinson, Madrid, 2010.

SAIZ ARNÁIZ. A., La apertura constitucional al derecho internacional y europeo de los derechos humanos: el artículo 10.2 de la constitución española, Consejo General del Poder Judicial, Madrid, 1999.

SÁNCHEZ, G., Introducción al Derecho Procesal, Marcial Pons, Madrid, 2013.

SAVIGNY, Sistema de derecho romano actual, tomo IV, Madrid pp.7-10.

SERRA DOMÍNGUEZ, M., Evolución histórica y orientaciones modernas del concepto de acción, en Revista de Derecho Procesal Iberoamericana, 1963, pp. 35-92 y

SILGUERO ESTAGNAN, J., La legitimación de los grupos, Dykinson, Madrid, 1995,

TARUFFO, M., Páginas sobre justicia civil, Marcial Pons, Madrid, 2009.

THE EUROPEAN COMMISSION FOR THE EFFICIENCY OF JUSTICE, Evaluation of European Judicial Systems, 2012.

TRAVESAS, M. M., La defensa privada, en Revista de Derecho Privado, 1915,

VÁZQUEZ SOTELO, J. L., El proceso de acciones colectivas (necesidad de su implantación en España), en Actualidad Civil, No 16, Sección A Fondo, Quincena del 16 al 30 Sep. 2011, tomo 2.

WACH, A., Der Feststellungsanspruch. Ein Beitrag zur Lehre vom Rechtsschutznspruch, Duncker \& Humbolt, Leipzig, 1889. 
WINDSCHEID, La "actio" del derecho civil romano desde el punto de vista del derecho actual, Düsselforf, 1856, La “actio”. Replica a Th. Muller, Dusseldorf, 1857.

ZANZUCCHI, M. T., Diritto Processuale Civile, I, $6^{\circ}$ ed., Giuffrè, 